\title{
LA COMERCIALIZACION \\ DE LA SEDA VALENCIANA \\ A FINALES DEL ANTIGUO REGIMEN: \\ EL “CONTRASTE" DE LA CIUDAD DE VALENCIA
}

\author{
RICARDO FRANCH BENAVENT \\ Universidad de Valencia
}

\section{1) Introducción. Fuentes y metodologia}

Como es bien conocido, el País Valenciano constituyó la principal área sericicultora en la España del siglo xvıı. Su desarrollo se había orientado, previamente, hacia el abastecimiento de los centros manufactureros castellanos y andaluces. Pero la progresiva decadencia que éstos experimentaron favoreció el surgimiento de una industria sedera autóctona que acabó absorbiendo la mayor parte de la materia prima producida por su agricultura'. Ahora bien, uno de los rasgos más destacados de la sedería valenciana fue su casi absoluta concentración en la ciudad de Valencia. Es esta circunstancia la que confiere una excepcional importancia al análisis de las relaciones comerciales que en ella se establecieron en torno a la materia prima sedera. Sus datos nos proporcionarán una preciosa información sobre el complejo mundo de los cosecheros y especuladores. Pero, al mismo tiempo, constituirán, sobre todo, un claro indice de la situación de la sedería y un fiel instrumento para conocer el comportamiento de los principales fabricantes.

Para lograr estos abjetivos disponemos de una fuente de excepcional importancia: los cuadernos de registro de operaciones de compra-venta de la seda que llevaba el fiel del contraste de la ciudad de Valencia. El contraste, es decir, el mercado en el que debía de comercializarse obligatoriamente la seda, constituía una de las piezas clave de la política de control de la materia prima sedera mantenida por la monarquía a lo largo de todo el siglo xvin. Si bien dicho control se fue atenuando a medida que la política económica se iba orientando hacia el liberalismo, las regulaciones que afectaban a la

' V. Martínez Santos ha insistido en la subordinación de la sedería valenciana al desarrollo previo de la sericicultura para explicar buena parte de los males que afectaron luego a aquélla, destacando entre ellos el enorme peso de los intereses agrarios y la vocación exportadora de la materia prima. Martínez Santos (1981). Véanse, por ejemplo, las pp. 257.258. Solte la escasa efectividad de la exportación legal de la materia prima durante la segunda mitad del siglo xvili y las expediciones realizadas hacia los restantes centros manufactureros españoles puede verse Franch (1989). 
comercialización de la seda en bruto se vieron poco afectadas ${ }^{2}$. En el caso de Valencia, el contraste se habia ubicado en el salón de columnas de la Lonja a partir de la cesión de este edificio al recién creado Cuerpo de Comercio en 1762. Fue también entonces cuando, aprovechando dicha ocasión, el intendente Avilés recopiló toda la legislación anterior relativa a la contratación de la seda, lo que nos permite conocer exactamente el marco jurídico en el que ésta se desenvolvía ${ }^{3}$. Según estas disposiciones, el contraste constituía el centro hacia el que tenía que afluir obligatoriamente toda la seda que se introdujese en Valencia, ya fuese para su venta, consumo o exportación, debiendo de quedar registrada en los libros que tenía que llevar el fiel a tal efecto. La finalidad de control de la materia prima introducida resulta evidente, y de ahí que se reservase la designación del fiel al colegio del arte mayor de la seda, en cuyo archivo debían de quedar custodiados los libros, «... pues han de servir de govierno para saber la seda que se ha contratado en las fábricas, la que se ha extraido, y el destino y paradero que ha tenido toda la que se ha introducido..." Para mayor claridad, se disponía que se anotasen en cuadernos separados la materia prima que se destinase al consumo de las fábricas y la que se introdujese de tránsito para la exportación. $Y$, con el fin de comprobar la valide\% de los datos, se garantizaba a los mayorales del arte mayor el acceso a los registros de introducción de productos que se llevaban en las diversas puertas de entrada de la ciudad.

Aunque el fiel del contraste dependía inicialmente del colegio del arte mayor de la seda, a partir de 1777 quedó vinculado a la Junta de Comercio de Valencia. Desde entonces, fue este organismo el que se encargó de recaudar el derecho de un maravedí por libra de seda que se comprase con licencia del intendente, impuesto que se destinaba a abonar los salarios del fiel y los seis veedores del contraste. Es quizá esta relación la que puede explicar la existencia entre los fondos de dicha institución de los registros del fiel del contraste a partir de finales de la década de 1770 . No obstante, su conservación es muy incompleta. Hasta el momento, sólo se han logrado localizar 12 registros anuales completos relativos a la época final del siglo xvirI, com-

- Así, por ejemplo, incluso en la Real Cédula de 1 de septiembre de 1772, en la que se sancionaba la vigencia del decreto de 1760 sobre liberalización parcial de la exportación de seda y se abolía la obligación de los cosecheros de manifestar la seda produ. cida anualmente, se seguía manteniendo, en cambio, el sistema de guías y torna-guias para controlar el tráfico de la materia prima entre los diversos lugares, y se reafirmaba la vigencia de los contrastes, ordenándose que en todos los existentes se estableciese, igual como existía en Murcia tradicionalmente, un fiel encargado de anotar todas las operaciones realizadas diariamente. Novisima Recopilación de las Leyes de España. Libro IX, Título XVI, Ley V, Madrid, 1805.

'AMV (Archivo Municipal de Valencia), Documentación Lonja, Caja 46.. 
prendidos entre 1778 y 1800 , y 22 registros anuales más fechados entre 1801 y $1859^{4}$.

Los registros localizados contenían todas las operaciones de compra-venta de la seda destinada al consumo de las fábricas de la ciudad de Valencia. Sólo en los primeros años se anotó también la materia prima vendida en el contraste que acabó siendo expedida hacia el resto de los centros manufactureros españoles, circunstancia que ya no vuelven a incluir los registros a partir de la década de 1780 . Igualmente, aunque sabemos que desde 1788 se importó continuamente seda extranjera, ésta sólo se refleja de una forma sistemática en los registros a partir de 1796 (previamente se anotaba en hojas separadas que nunca se han localizado íntegramente). En todo caso, la información proporcionada por la fuente es muy minuciosa, puesto que en cada operación realizada se detalla la fecha de su realización, el corredor que intervino en ella, el nombre del vendedor y su lugar de origen, el nombre del comprador, y la calidad, precio y peso de la seda intercambiada. Ahora bien, es la propia riqueza informativa de la fuente lo que constituye la principal dificultad a la hora de abordar su análisis. En efecto, teniendo en cuenta la entidad de la sedería valenciana, es fácil deducir que el volumen de operaciones que se efectuaban anualmente en el contraste era considerablemente elevado, hasta el punto de hacer casi inmanejable el tratamiento de tal cantidad de datos. Valga como muestra, por ejemplo, el hecho de que en el año 1796 se ha llegado a contabilizar un total de 12.937 operaciones de compra-venta, lo que, teniendo en cuenta que cada una de ellas abarca ocho campos de información, supone el tratamiento de más de 100.000 datos. Lógicamente, tal cantidad de información sólo puede ser aceptablemente manejada mediante la utilización de la informática ${ }^{5}$. Pero, aun así, la considerable cantidad de tiempo y de trabajo que requiere la introducción y tratamiento de tantos datos me ha obligado a limitar el estudio al análisis en profundidad de un solo año.

Afortunadamente, a partir de 1796 los registros solian contener un resumen anual en el que se indicaba la cantidad y calidad de la seda comercializada

+ Los registros del contraste que van a ser utilizados en el presente trabajo se encuentran custodiados en la sección "Documentación Lonja» del Archivo Municipal de Valencia. La referencia concreta es la siguiente: cosecha de $1778=$ Caja 40 , año 1796 = Caja $64_{2}$, año 1798 = Caja 44, año 1800 = Caja 21, año 1801 = Caja 41, año 1802 = Caja $5_{1}$, año 1805 = Caja 37 , año 1806 = Caja 401 , año 1810 = Caja $57_{1}$, año 1811 = Caja $49_{2}$, año 1812 = Caja 64 , año 1816 = Caja 3 , año 1821 = Caja $64_{1}$, año $1822=$ Caja 79 , año $1835=$ Caja 42 . Los restantes registros conservados no han sido utilizados bien porque no contenían el resumen inicial o bien porque cran posteriores a 1835 y no reflejaban cambios sustanciales.

Agradezco al doctor Rafael Benítez Sánchez-Blanco la ayuda que me ha prestado en este aspecto, proporcionándome los rudimentos informáticos básicos para el manejo con pleno provecho de los datos obtenidos. 
mensualmente, lo que ha permitido conocer con bastante facilidad tanto el ritmo como la entidad de la materia prima intercambiada en los años conservados. Con el fin de comprobar su representatividad para los años previos, se procedió a calcular manualmente las cantidades de seda intercambiadas en el primer año conservado, es decir, la cosecha de 1778 , lo que, por sí solo, ya supuso un trabajo muy considerable. Disponiendo, pues, de este marco de referencia, se adoptó el año 1796 como la muestra que podía ser susceptible de un estudio en profundidad. Se trataba de un año en el que el volumen total de la materia prima intercambiada se situaba dentro de unos niveles habituales. Pero, además, a esta circunstancia de normalidad se añadía el hecho de que en dicho año se había introducido la mayor cantidad de seda extranjera que se conoce en el período examinado. Por tanto, su estudio permitía enriquecer notablemente el análisis, puesto que a la acción de los ven. dedores y compradores habituales se sumaba la intervención de los importadores y vendedores de seda extranjera. Esta doble circunstancia creo que justifica suficientemente la elección realizada.

Cabe aludir, finalmente, a la fiabilidad de los datos contenidos en los registros. En este sentido, la controntación de éstos con las cifras derivadas de los registros de entrada por las puertas de la ciudad de Valencia induce hacia el optimismo. En efecto, en 1772 el administrador de la renta del 8 por 100 certificaba que la seda introducida en la ciudad de Valencia "... para el consumo de sus fábricas..." había ascendido en el año 1770 a 476.451 libras, cantidad que se redujo a 295.181 libras en 1771 debido a la pésima cosecha de este año ${ }^{6}$. Igualmente, entre 1789 y 1793 la seda introducida inicialmente para el consumo de las fábricas había oscilado entre un mínimo de 415.649 libras en 1790 y un máximo de 500.335 libras en 1792 , cantidades que podian ser reclucidas a 388.596 libras y 461.355 libras, respectivamente, si se perfilaban más los datos ${ }^{7}$. En todo caso, las cifras aludidas concuerdan perfectamente con las derivadas de los intercambios efectuados en el contraste a fines del siglo xvill y principios del xix. No cabe duda, pues, que los datos del contraste pueden constituir un fiel reflejo de la situación de la sedería ${ }^{8}$, al menos considerando las cantidades que afluían hacia ella de forma legal.

- AGS (Archivo General de Simancas), Secretaría de Hacienda, Leg. 1729.

' AMV, Documentación Lonja, Caja 80 . En concreto, a las cifras iniciales cabía añadirles las cantidades que se habían introducido de tránsito y que acabaron siendo retenidas por las fábricas, y restarles, en cambio, las que se expidieron hacia otras zonas de España tras haberse vendido en el contraste.

- En este aspecto, la situación era muy distinta en el caso de Murcia debido, entre otros factores, a la escasa entidad de su sedería. De ahí que los corretajes percibidos en el contraste hayan sido utilizados, en este caso, como una fuente para analizar la evolución de la producción sedera. Véase Pérez Picazo y Lemeunier (1987). Sobre la misma cuestión puede verse también Olivares (1976). 
II) Evolución y ritmo cronológico de la comercialización de la seda

Como se ha indicado anteriormente, la conservación de resúmenes anuales a partir de 1796, junto con la cata efectuada en la cosecha de 1778, nos ha permitido conocer la evolución de la materia prima comercializada en el contraste a fines del Antiguo Régimen, revelándonos, además, perfectamente el ritmo cronológico con el que se producían las ventas. Los resultados globales han sido plasmados en el cuadro 1 .

\section{CUADRO 1}

Evolución y ritmo de ventas de la seda comercializada en el contraste de Valencia a fines del Antiguo Régimen

(Datos en libras valencianas)

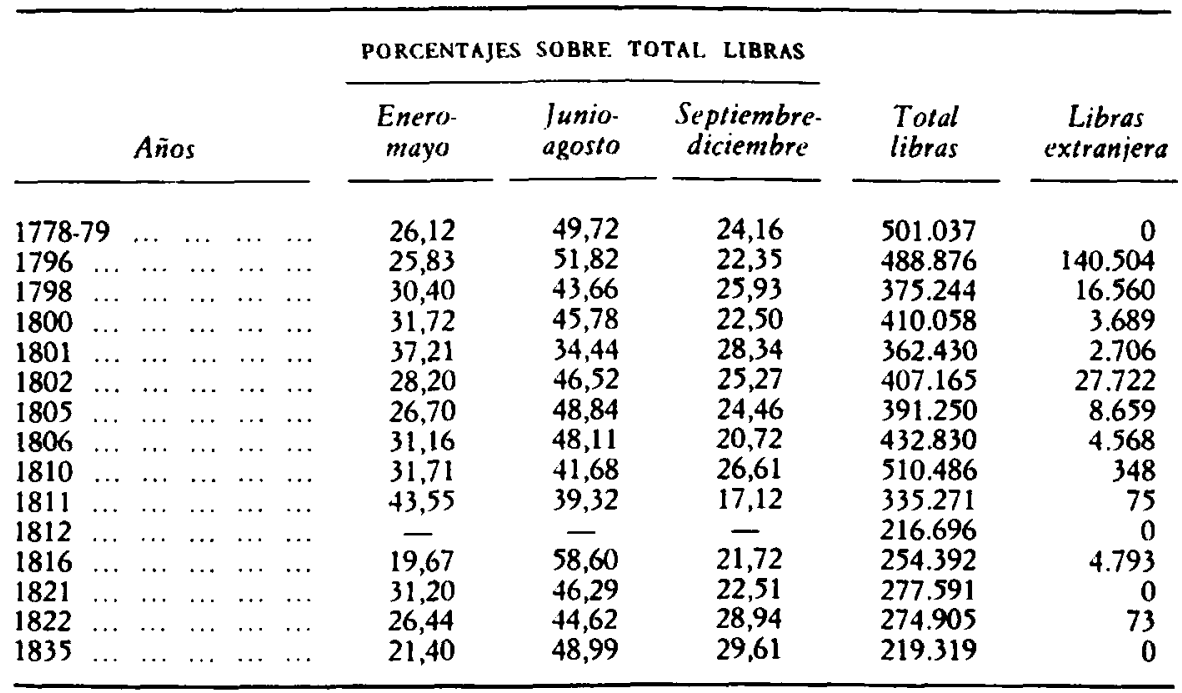

FUENTE: Véase la nota 4.

Su lectura evidencia perfectamente, en primer lugar, la relativa decadencia experimentada por la sedería a partir de la década de 1810 . Hasta entonces. la materia prima comercializada en el contraste superaba habitualmente las 400.000 libras. Sólo en tres de los nueve años conocidos entre 1778 y 1810 no se llegó a alcanzar esta cifra, y dos de ellos se situaban en el período más álgido de paralización de la actividad comercial a raíz del bloqueo im- 
puesto por Inglaterra. Pero, en contraposición, existieron también dos años en que se superó la cantidad de 500.000 libras. En realidad, como hemos podido ver, los datos de dicho período concuerdan perfectamente con los derivados de los registros de entrada por las puertas de Valencia en 1770-1771 y 1789-1793, lo que induce a pensar que la sedería valenciana habia tocado techo en el último tercio del siglo xvill, oscilando sus necesidades habituales de materia prima entre las 400.000 y 500.000 libras ${ }^{9}$. Sin embargo, a partir de 1811 el volumen de seda comercializada en el contraste se situó normalmente por debajo de las 300.000 libras, cantidad raras veces superada en los años conservados de la primera mitad del siglo xix. Es decir, la reducción realizada en estos años con respecto a los niveles habituales de fines del siglo xvili alcanzó un mínimo del 25 por 100, llegándose en algunos casos hasta cifras inferiores en un 50 por 100 a las de los mejores ejercicios de aquel período ${ }^{10}$.

La misma sensación de decadencia revela también la evolución de la seda extranjera comercializada en el contraste. Desgraciadamente, no disponemos de referencias previas que nos permitan calibrar adecuadamente la elevada cifra de 1796. En todo caso, ésta se enmarca en un período de continuas importaciones de seda extranjera que pudo haber conducido a una parcial sustitución de la materia prima autóctona ", a cuyas deficiencias en el proceso de hilado y torcido se solía achacar la mala calidad de los tejidos valencianos. En este sentido, la continua presencia en el contraste de la seda extranjera en los años conservados entre 1798 y 1810 , a pesar de la paralización del comercio internacional que existió durante buena parte del período, puede poner de manifiesto la atracción que los fabricantes valencianos sentían por ella. Sin embargo, coincidiendo con el brusco descenso de la materia prima comercializada en el contraste, la seda extranjera comienza a ser irrelevante a

- Esta misma idea de estabilidad o estancamiento en un nivel elevado es la que se desprende del análisis de la cantidad total de telares anchos existentes entre 1760 y 1797. puesto que la cifra de telares corrientes, que es la que utiliza Martínez Santos para reflejar la evolución de la sedería, carece de homogeneidad, como veremos posteriormente. Véase Martínez Santos (1981), pp. 96 y 144. Con respecto a las cantidades contenidas por el cuadro 1, debe advertirse que en la cosecha de 1778 no se han incluido las 44.161 libras que se vendieron en el contraste y se expidieron luego a los centros manufactureros del resto de España, ya que esta circunstancia no se indica ya en los registros utilizados posteriormente.

"Para el primer tercio del siglo xix. Martínez Santos defiende la existencia de una reducción en el número de telares de la sedería valenciana de alrededor del $56 \%$ de los existentes en la década de 1780. Véase Martínez Santos (1981), p. 171. Sobre la evolución del número de telares corrientes de esta época, véase p. 144.

"Sobre las importaciones valencianas de seda extranjera, véase Franch (1989), pp. 77. 81. Hay que tener en cuenta que las cifras contenidas en este trabajo se referian exclusivamente a las importaciones directas efecruadas por el puerto de Valencia, mientras que en el contraste se comercializaba también seda extranjera que había sido importada por otros puertos españoles y que se había remitido luego a esta ciudad. 
partir de la década de 1810 , y desaparece completamente de los registros del contraste conservados después de 1822.

Pero, aparte de revelar la decadencia de la sedería, el cuadro 1 pone también de manifiesto el ritmo anual con el que se producía la comercialización de la seda. En este sentido, los datos no pueden ser más concluyentes, puesto que reflejan perfectamente la persistencia de un ciclo anual característico que experimenta escasas variaciones, independientemente del volumen total de la materia prima comercializada (esta circunstancia puede apreciarse con mayor detalle en el apéndice numérico I). Lógicamente, dicho ciclo se halla directamente relacionado con el origen agrario de la producción sedera. Como es conocido, ésta se obtenía en la segunda mitad del mes de mayo, y, a partir de entonces, se iniciaba un rápido proceso de comercialización que se manifestaba, en el caso del contraste, en el hecho de que casi la mitad del volumen anual de las ventas se concentrasen en el trimestre comprendido entre junio y agosto. Posteriormente, el ritmo se ralentizaba, dando lugar a que en los nueve meses restantes del año se distribuyesen las operaciones de una forma bastante homogénea. Así, en el cuatrimestre comprendido entre septiembre y diciembre se comercializaba entre el 20 y el 25 por 100 del total anual, y una proporción algo más elevada se enajenaba entre enero y mayo, mes este último en el que ya comenzaba a venderse la seda de la nueva cosecha.

Cabe resaltar que el ritmo anual de la comercialización es prácticamente idéntico al que constatamos por medio del estudio de los registros de «sacas» de Alberique en la segunda mitad del siglo xviII ${ }^{12}$. Pero, además, como ya evidenciamos entonces, aquél parecía estar estrechamente relacionado con el distinto comportamiento de los vendedores de seda. En el caso del contraste de Valencia, el fenómeno se puede apreciar con mayor claridad en el año $1796^{13}$, al conocer también entonces el número de partidas en que se distribuyeron las ventas, y, consiguientemente, la entidad media que tenían aquéllas. Estos datos son los que han sido reflejados en el cuadro 2.

1: Franch y Andrés (1983), pp. 130-132.

"La cantidad total de seda comercializada en el contraste en el año 1796 que se ha obtenido a partir del tratamiento informático de las partidas contenidas en el registro del fiel ha ascendido a 494.361,58 libras. Como puede apreciarse, se trata de una cantidad superior en 5.485 libras a la que figuraba en el resumen inicial de dicho registro, que es la cifra que se ha incluido en el cuadro 1. Esta diferencia puede deberse bien a las deficiencias de los procedimientos de contabilidad en el Antiguo Régimen, o bien a posibles errores cometidos en el tratamiento de una cantidad tan clevada de partidas. En todo caso, creo que el margen de error resultante, que se situaría en torno al $1 \%$, es aceptable, y difícilmente puede alterar sustancialmente las conclusiones obtenidas. Cabe advertir que la cifra obtenida a partir de la claboración personal de los datos es la que se va a utilizar en los cuadros sucesivos. 


\section{CUADRO 2}

Ritmo de comercialización de la seda en el contraste de Valencia en el año 1796

(Datos en libras valencianas)

\begin{tabular}{|c|c|c|c|c|c|}
\hline Meses & Partidas & \% total & Libras & os total & Media \\
\hline Enero-mayo $\ldots \ldots \ldots$ & 2.237 & 17,29 & $127.871,54$ & 25,87 & 57.16 \\
\hline Junio-agosto $\ldots \ldots \ldots$ & 8.598 & 66,46 & $255.561,44$ & 51.69 & 29,72 \\
\hline Septiembre-diciembre . & 2.102 & 16,24 & $110.928,55$ & 22,44 & 52,77 \\
\hline Total . ........ & 12.937 & 100,00 & $494.361,58$ & 100,00 & 38,21 \\
\hline
\end{tabular}

Fuente: AMV, Documentación Lonja, Caja $64_{2}$.

De su lectura se desprende claramente la elevada concentración de operaciones que tenía lugar en los meses inmediatamente posteriores a la cosecha, una concentración muy superior a la de la cantidad de seda comercializada en dicho período, lo que determinaba que la media que alcanzaba cada partida se situase casi en la mitad de los niveles obtenidos en el resto del año. En efecto, entre junio y agosto la media por partida era de 29,72 libras, cantidad que contrastaba claramente con las 57,16 libras de media que se conseguían entre enero y mayo. Pero aquella cifra aún descendía hasta las 22,04 libras en el mes de junio, cuando se concentraban el 39,92 por 100 de las partidas anuales y se comercializaba el 23,02 por 100 de la seda. No cabe duda que ello se debía a la afluencia al mercado de los pequeños cosecheros que necesitaban enajenar rápidamente su reducida producción con el fin de hacer frente a las cargas más inmediatas que afectaban a sus explotaciones. Por el contrario, en los meses más alejados de la cosecha era cuando entraban en acción los grandes productores y especuladores, cuyos mayores recursos les permitían efectuar sus ventas cuando el mercado se hallaba más desabaste. cido, aprovechándose, por tanto, del alza de precios que ello determinaba. Posteriormente tendremos ocasión de profundizar más en esta línea. 


\section{CUADRO 3}

Calidad y precio de la seda vendida en el contraste de Valencia. Año 1796 (Cantidad en libras y precio en reales valencianos)

\begin{tabular}{|c|c|c|c|}
\hline Calidades & Libras & 90 total & Precio medio \\
\hline 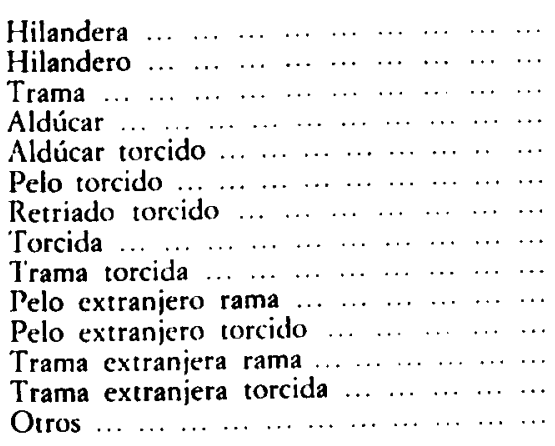 & $\begin{array}{r}169.129,07 \\
35.417,58 \\
100.557,81 \\
20.315,04 \\
535,29 \\
6.840,50 \\
204,67 \\
695,54 \\
18.953,71 \\
5.926,50 \\
57.253,33 \\
1.529,42 \\
76.048,46 \\
954,67\end{array}$ & $\begin{array}{r}34,21 \\
7,16 \\
20,34 \\
4,11 \\
0,11 \\
1,38 \\
0,04 \\
0,14 \\
3,83 \\
1,20 \\
11,58 \\
0,31 \\
15,38 \\
0,19\end{array}$ & $\begin{array}{l}42,42 \\
42,05 \\
41,59 \\
23,42 \\
35,15 \\
53,17 \\
41,33 \\
49,53 \\
47,11 \\
43,98 \\
61,36 \\
41,32 \\
50,23 \\
-\end{array}$ \\
\hline $\begin{array}{lllllllll}\ldots & \ldots & \ldots & \ldots & \ldots & \ldots & \ldots & \ldots\end{array}$ & $494.361,59$ & 100,00 & \\
\hline
\end{tabular}

Fuente: AMV, Documentación Lonja, Caja 64:.

Como se ha acabado de apuntar, la estacionalidad con la que se producían las ventas provocaba la aparición de un ciclo anual en la evolución de los precios de la seda. Lógicamente, el precio de la materia prima alcanzaba un nivel distinto según la calidad de que se tratase. A partir de los resúmenes anuales contenidos por los registros del contraste desde 1796 podemos deducir que alrededor de la tercera parte de la seda comercializada anualmente pertenecía a la calidad «hilandera»; un porcentaje similar alcanzaba la seda «trama»; y el tercio restante se distribuía entre la seda «hilandero», que solía constituir en torno al 10 por 100 del total; la «torcida", que rondaba también dicho porcentaje; la «aldúcar», que constituía en torno al 5 por 100 , y la seda extranjera, que, salvo en 1796 (en que alcanzó el 28 por 100), oscilaba entre el 0 y el 7 por 100. Pues bien, a partir de los datos elaborados en 1796 podemos deducir que la seda «hilandera», "trama» e «hilandero», es decir, las tres calidades más representativas, alcanzaban un nivel medio de precios bastante similar, que en dicho año se situaba entre los 41,5 y 42,5 reales valencianos por libra ${ }^{14}$. En el caso de la seda de inferior calidad, el aldúcar,

14 Sorprendentemente, $y$ sin que conozcamos exactamente el motivo, el nivel de 
el precio se reducía casi a la mitad, hasta los 23,42 reales valencianos por libra en 1796. Por el contrario, cuando la seda se hallaba torcida, el precio se elevaba, siempre en el año analizado, hasta los 47 reales, en el caso de la trama, o los 53 reales, en el caso del pelo. Finalmente, con respecto a la seda extranjera, su nivel de precios era similar al de las principales calidades cuando se importaba en rama (entre 41 y 44 reales en 1796). Pero, como puede apreciarse en el cuadro 3, to habitual era que se importase ya torcida, en cuyo caso el precio se situaba en los 50 reales valencianos para la trama y los 61 reales para el pelo, calidad que alcanzaba el nivel de precios más elevado.

\section{CUADRO 4}

Movimiento estacional de los precios de la seda en el contraste de Valencia. Año 1796

\begin{tabular}{|c|c|c|c|c|c|c|c|}
\hline Meses & $\begin{array}{c}\text { Hilan } \\
\text { dera }\end{array}$ & $\begin{array}{c}\text { Hilan } \\
\text { dero }\end{array}$ & Trama & $\begin{array}{l}\text { Trama } \\
\text { torcida }\end{array}$ & Aldúcar & $\begin{array}{l}\text { Trama } \\
\text { ex. tor. }\end{array}$ & $\begin{array}{c}\text { Pelo } \\
\text { ex. tor. }\end{array}$ \\
\hline$\ldots \ldots \ldots$ & 10,89 & 10.32 & 9,57 & 6,43 & $-0,83$ & 13,38 & 3,60 \\
\hline Febrero $\ldots \ldots \ldots$ & 9,57 & 9.58 & 10,84 & 10,02 & -0.51 & 10,83 & 0,10 \\
\hline Marzo . ... . . . . & 3,44 & 5,18 & 6,40 & 7,49 & 1,02 & 8,36 & 2,18 \\
\hline Abril $\ldots \ldots \ldots$ & 3,11 & 5,21 & 7,19 & 7,47 & 1,84 & 3,70 & 0,55 \\
\hline Mayo . ... ... ... & 2,78 & 5,68 & 5,94 & 5,33 & 0,16 & 4,62 & 1,17 \\
\hline Junio . ... $\ldots \ldots$ & $-3,32$ & $-1,62$ & -0.41 & 1,02 & $-2,08$ & $-3,78$ & $-0,57$ \\
\hline Julio $\ldots \ldots \ldots c$ & $-1,89$ & $-0,29$ & $-0,58$ & 0,91 & 0,28 & 0,98 & 1,04 \\
\hline Agosto $\ldots \ldots \ldots$ & $-2,10$ & $-2,54$ & $-2,64$ & $-1,59$ & 1,57 & $-2,49$ & 0,52 \\
\hline Septiembre ... ... & $-7,17$ & $-10,30$ & $-9,91$ & $-11,82$ & $-1,31$ & $-6,93$ & $-4,73$ \\
\hline Octubre ... ..... & $-8,13$ & $-8,82$ & $-11,49$ & $-8,66$ & 0,16 & $-9,50$ & $-1,14$ \\
\hline Noviembre ... ... & $-3,37$ & $-6,33$ & $-7,50$ & $-6,60$ & $-0,33$ & $-10,03$ & -3.75 \\
\hline $\begin{array}{lll}\text { Diciembre } & \ldots & \ldots\end{array}$ & $-3,70$ & $-6,11$ & $-7,31$ & $-10,00$ & $-0,14$ & $-9,16$ & 0,91 \\
\hline
\end{tabular}

Fuente: AMV, Doxumentación Lonja, Caja $64_{2}$

precios que reflejan los datos del contraste es inferior en cerca de un $50 \%$ al obtenido por J. M. Palop a partir del Diario de Valencia. Palop (1977). Véanse los datos de la p. 270 . 
En todas las calidades señaladas los precios anuales experimentaban un claro ciclo estacional, según refleja el cuadro 4. La amplitud de la variación era bastante elevada, salvo en el caso del aldúcar y el pelo torcido extranjero, puesto que en 1796 se situ:ba en torno al 20 por 100. Esta proporción puede considerarse como habitual, a tenor de los resultados derivados de las series trabajadas por J. M. Palop 's. En cambio, la cronología del movimiento que se ha extraído de éstas es algo distinta a la que aparece en las ventas efectuadas en el contraste. En las series del Diario de Valencia los precios más bajos se alcanzaban en los meses centrales del verano, siendo superiores a la media anual ya a partir de los meses de octubre o noviembre, y alcanzando su nivel más elevado en enero y febrero. En los datos derivados del contraste se daba también este último extremo, pero, en cambio, los precios más bajos parecían extenderse a lo largo de toda la segunda mitad del año, alcanzando su nivel más profundo en los meses de septiembre y octubre, y no en los inmediatamente posteriores a la cosecha. Incluso en el caso de la seda torcida, los precios superaban aún la media anual en los primeros meses del verano, debido, seguramente, a que el período de tiempo requerido para que pudiese efectuarse adecuadamente esta operación retrasaba su salida masiva al mercado ${ }^{16}$. En todo caso, lo que cabe destacar es la elevada am. plitud de la variación estacional y la obtención de los precios más elevados en los cinco primeros meses del año anteriores a la cosecha, factores que nos ayudarán a localizar y explicar la aparición de comportamientos especulativos entre algunos de los principales vendedores.

\section{III) Los vendedores de seda en el contraste: sus origenes geográficos $y$ sus diversas estrategias de comercialización}

La concentración en la ciudad de Valencia de la práctica totalidad de la manufactura sedera valenciana convertía al contraste en un extraordinario polo de atracción hacia el que afluían vendedores de seda originarios de los más diversos lugares. Así consta, al menos, en el registro de 1796, que ha sido analizado en profundidad. Según sus datos, los vendedores procedieron entonces de 338 localidades distintas. De ellas, sólo cinco se hallaban fuera de los límites del actual País Valenciano. aunque a éstas se deberían añadir

"Palop (1977). Véanse pp. 270-271.

in En el informe emitido por la Junta de Comercio de Valencia sobre el estado de la sedería en el año 1800 se indicaba que la seda de la nueva cosecha tardaba un mínimo de dos meses en recibir todas las operaciones previas al tejido. AMV. Documentación Lonja, Caja +3. 
otras 45 que no se han logrado localizar. En todo caso, estas 50 localidades sólo aportaron algo menos del 1,30 por 100 de la materia prima total vendida en el contraste en 1796. Por tanto, el primer rasgo que cabe destacar es que casi toda la seda enajenada en el contraste procedía de vendedores resi dentes, con toda seguridad, en el País Valenciano.

Ahora bien, como ya se ha indicado previamente, en el año 1796 existió una cantidad muy elevada de seda extranjera comercializada en el contraste. Se trataba, según los cálculos efectuados a partir de los datos de los registros, de 140.757,66 libras ${ }^{17}$. De esta cifra, sólo 427,66 libras fueron vendidas por un comerciante de Barcelona. Las restantes 140.330 libras procedían, por el contrario, de vendedores residentes en la ciudad de Valencia. Cabe, pues, tener siempre presente el peso que esta concentración suponía a la hora de interpretar los resultados proporcionados por las ventas de seda en el contraste. Realmente, los vendedores de seda extranjera presentan unos rasgos específicos que merecen un análisis detenido, como veremos posteriormente.

La seda extranjera debe ser marginada, en principio, con el fin de proceder al análisis del origen geográfico de los vendedores. De esta forma se podrá obtener un índice bastante indicativo de la irradiación que alcanzaba el mercado de la ciudad de Valencia sobre las áreas rurales del resto del país, teniendo en cuenta, claro está, la diversa entidad productiva que alcanzaba la materia prima sedera en cada una de ellas. Con esta matización, cabe subrayar que al contraste afluyeron en 1796 vendedores procedentes de la práctica totalidad de las comarcas en las que actualmente se halla dividido el País Valenciano. En efecto, una somera distribución comarcal de aquéllos revela que, de las 32 que se admiten habitualmente, sólo las tres existentes en el bajo y medio Vinalopó se hallaban ausentes. Por tanto, la influencia del mercado de Valencia era muy considerable, extendiéndose a lo largo de casi toda la superficie del antiguo Reino. Ahora bien, la intensidad que alcanzaba esta influencia era muy diversa, puesto que, atendiendo a la entidad de la seda comercializada, sólo en 13 de las 29 comarcas aludidas las ventas efectuadas superaban las 2.000 libras. Aquéllas son las que han sido reflejadas en el cuadro 5, aunque en el caso de la comarca de L'Horta se han extraido los vendedores residentes en la ciudad de Valencia y se han considerado inde. pendientemente debido a su elevada importancia. Dichas comarcas se hallaban ubicadas, salvo en el caso de Els Ports, en el área central del País Valenciano, extendiéndose a lo largo de toda la fachada litoral comprendida entre la

${ }^{17}$ Como puede apreciarse, la diferencia con respecto a la cifra que constaba en el resumen inicial del registro de 1796 , que es la que se ha reflejado en el cuadro 1 , resulta insignificante, al ascender sólo a 253,66 libras, lo que supone una desviación del 0,18 por 100 . 


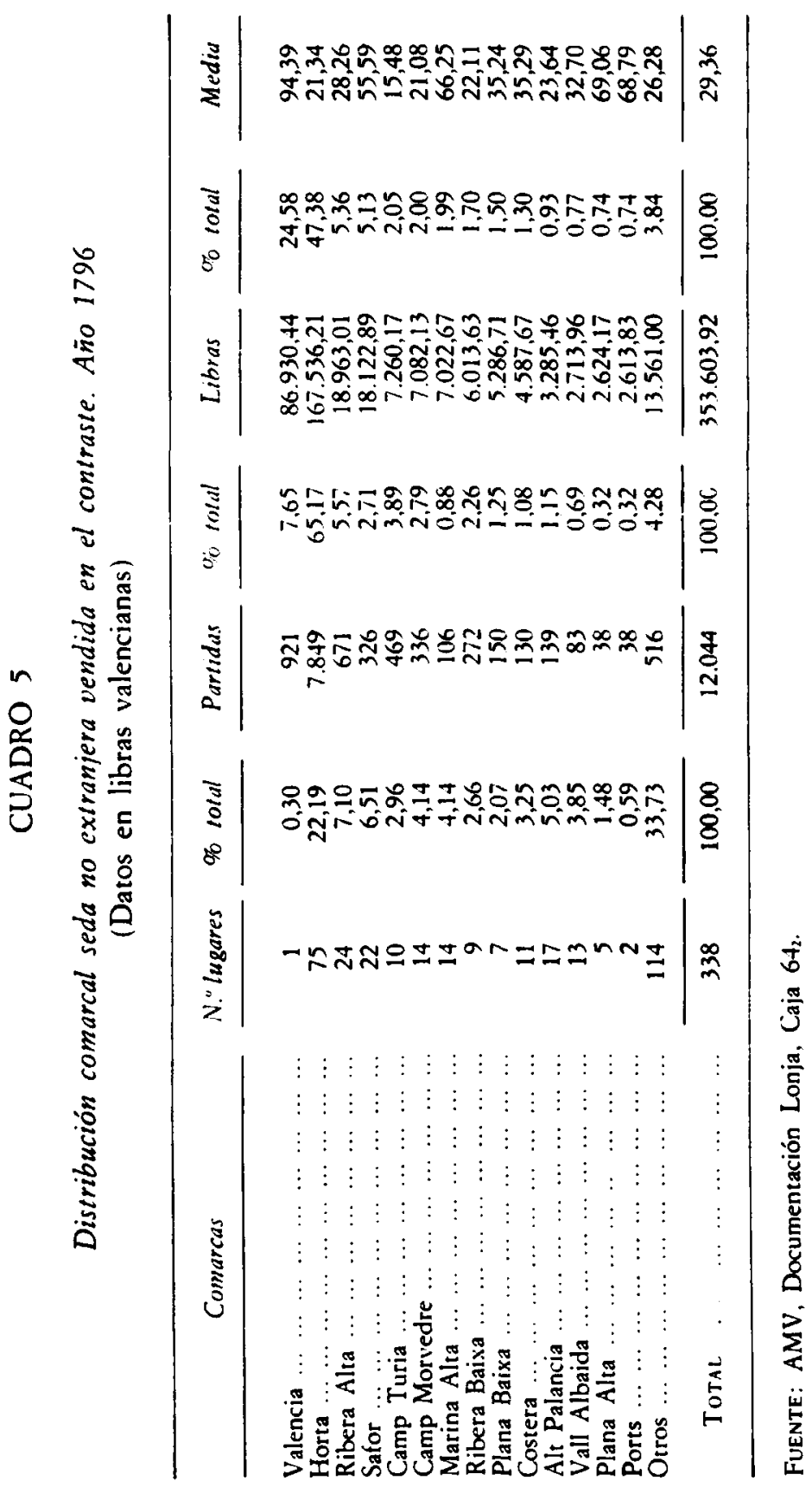


Plana Alta y la Marina Alta, con una mayor penetración hacia las áreas interiores dentro de los límites de la actual provincia de Valencia. En realidad, su distribución se correspondía bastante con la de las principales zonas productoras de seda ${ }^{18}$.

No obstante, cabe destacar la elevada entidad que en los registros del contraste alcanzaban los vendedores procedentes de la comarca de L'Horta y, dentro de ella, de la propia ciudad de Valencia. Desde luego, hay que tener en cuenta que, según el manifiesto de 1767, la gobernación de Valencia era la principal zona productora de seda, representando entonces algo más del 25 por 100 de la producción total declarada. Por tanto, todo induce a pensar que la cosecha de esta zona se canalizaba de una forma casi absoluta hacia el mercado de la ciudad de Valencia, que tendría en ella su principal área de influencia, mientras que las restantes comarcas destinarían una parte mayor de su producción a la expedición hacia los otros centros manufactureros españoles.

Por lo demás, las ventas efectuadas por las personas residentes en la ciudad de Valencia tenían una significación muy distinta a las que realizaban los residentes en las áreas rurales de sus inmediaciones. En efecto, en aquélla existían grandes cosecheros, rentistas y comerciantes que podían acumular elevadas cantidades de materia prima y realizar, en algunos casos, operaciones de carácter especulativo. No en vano la entidad media de las partidas enajenadas por personas residentes en Valencia alcanzaba las cifras más elevadas. con 94,39 libras (cantidad que se elevaba hasta 125,42 libras por partida si se incluía la seda extranjera). Por el contrario, en las áreas rurales próximas a la capital la mayor parte de las ventas eran realizadas por pequeños campesinos que comercializaban en el contraste su exigua producción. De ahí que entre los residentes en la comarca de L'Horta la media por partida se situase significativamente en 21,34 libras, cantidad aún superior, no obstante, a las 21,08 libras o las 15,48 libras por partida que suponían las ventas de los residentes en las comarcas del Camp de Morvedre y del Camp de Turia, respectivamente, comarcas que se hallaban englobadas en su mayor parte en la gobernación de Valencia y que, por tanto, se veían muy afectadas por la influencia de la capital. Por lo demás, a medida que los vendedores de seda

18 Según los datos del manifiesto de 1767, que es el único que se ha logrado loca. lizar en el que se indica someramente la distribución geográfica de la producción obtenida, las gobernaciones de Valencia, Alcira, San Felipe y Denia constituían las principales zonas productoras de seda, representando el 79 por 100 de la cosecha declarada. Estas gobernaciones abarcaban la mayor parte de las 13 comarcas aludidas, a las que cabe añadir las gobernaciones de Castellón y Morella, yue en 1767 representaban el 8.42 por 100 de la cosecha declarada. Realmente, de las principales áreas productoras, solamente no se hallan representadas en el cuadro 5 las gobernaciones de Orihuela y Peñiscola, que en 1767 suponían el 8,65 por 100 y el 2,25 por 100 , respectivamente, de la producción declarada. Sobre el manifiesto de 1767, véase AGS, Secretaría de Hacienda, Lez. 578. 
residían en lugares más alejados de la ciudad de Valencia parecían reaparecer, de nuevo, las operaciones de mayor entidad, como revelan las 55,59 libras de media por partida que se alcanzaba en la Safor (debido a la acción de los vendedores de Gandía), la: 66,25 libras de la Marina Alta (por las ventas, sobre todo, de Denia, Pego y Sagra), o, en el norte del país, las 68,79 libras de Els Ports (Forcall, Zorita, etc.), y las 69,06 libras de la Plana Alta (básicamente por la acción de Castellón).

De todas formas, la diversa realidad que existía detrás de la comercialización de la seda se evidencia mejor procediendo a un análisis del ritmo estacional en el que ésta tenia lugar. Esta circunstancia es la que se ha tratado de reflejar en el cuadro 6 para los 16 lugares cuyos residentes vendieron en el contraste más de 3.000 libras de seda en 1796. Hay que tener en cuenta que éstos proporcionaron más del 73 por 100 de la seda total vendida en dicho año (porcentaje que sólo descendía al 63,36 por 100 si se eliminaba la seda extranjera), por lo que sus resultados pueden considerarse absolutamente representativos. Igualmente, su distribución geográfica era muy semejante a la general, puesto que 12 de los 16 lugares aludidos pertenecen a la comarca de L'Horta, y los otros cuatro (Gandía, Carcagente, Alcira y Játiva) se ubican en las comarcas de la Safor, la Ribera Alta y la Costera. Precisamente son éstos, junto con Valencia, los que presentan un comportamiento vendedor muy distinto de la tónica general. En efecto, en 12 de los 16 lugares aludidos (pertenecientes todos a la comarca de L'Horta, más el caso de Alcira) se producía una intensa concentración de las ventas en los meses de junio, julio y agosto. La proporción de seda que enajenaban entonces con respecto a la total anual era muy superior a la que, como hemos visto en el cuadro 1, se lograba habitualmente en esos meses, puesto que oscilaba entre un mínimo del 63 por 100 y un máximo del 87 por 100 . Este hecho, junto con la escasa entidad media de las partidas enajenadas, que solía rondar en torno a las 20 libras, induce a pensar que casi todos los vendedores eran pequeños campesinos que se apresuraban a comercializar su producción al verse acuciados por sus necesidades económicas. Valga como ejemplo el com. portamiento de los vendedores de la Particular Contribución, que, después de Valencia, eran los que mayor cantidad de seda enajenaron en 1796 (nada menos que $76.048,46$ libras, el 15,38 por 100 de la seda total comercializada). Pues bien, el 79 por 100 de dicha cifra fue vendido en los meses inmediatos a la cosecha por una multitud de pequeños cosecheros y en unas partidas tan diminutas que, incluso con un tratamiento informático, resultan inmanejables. 


\section{CUADRO 6}

Ritmo estacional de las ventas de seda de los principales lugares (Datos en libras valencianas)

\begin{tabular}{|c|c|c|c|c|c|}
\hline \multirow[b]{2}{*}{ Lugares } & \multicolumn{3}{|c|}{ PORCENTAJES SOBRE TOTAI. LIBRAS } & \multirow[b]{2}{*}{$\begin{array}{l}\text { Tolal } \\
\text { libras }\end{array}$} & \multirow[b]{2}{*}{$\begin{array}{l}\text { Media } \\
\text { libras }\end{array}$} \\
\hline & $\begin{array}{l}\text { Enero- } \\
\text { mayo }\end{array}$ & $\begin{array}{l}\text { Junio- } \\
\text { agosto }\end{array}$ & $\begin{array}{l}\text { Septiembre- } \\
\text { diciembre }\end{array}$ & & \\
\hline Valencia (con extr.) ... & 33,44 & 37,90 & 28,66 & $227.260,48$ & $125,+2$ \\
\hline Valencia ( $\sin$ extr.) ... & 31,37 & 40,15 & 28,47 & $86.930,44$ & 94,39 \\
\hline Particular Contrib. . ... & 12,99 & 79,13 & 7,88 & $76.048,46$ & 21,65 \\
\hline Gandía $\ldots \ldots \ldots \ldots \ldots$ & 52,12 & 37,03 & 10,85 & $12.557,25$ & 80,50 \\
\hline $\begin{array}{llllll}\text { Puig } & \ldots & \ldots & \ldots & \ldots & \ldots\end{array}$ & 4,15 & 87,34 & 8,51 & $6.251,67$ & 16,31 \\
\hline 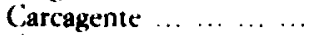 & 50,64 & 35,93 & 13,43 & $5.043,54$ & 40,35 \\
\hline Campanar $\ldots \ldots \ldots \ldots$ & 22,26 & 70,81 & 6,93 & $4.079,04$ & 38,85 \\
\hline $\begin{array}{llllll}\text { Alcira } & \ldots & \ldots & \ldots & \ldots & \ldots \\
\end{array}$ & 12,91 & 67,72 & 19,37 & $3.759,04$ & 38,36 \\
\hline$\ldots \ldots \ldots$ & 15,97 & 71,34 & 12,69 & $3.573,58$ & 21,66 \\
\hline Torrente $\ldots \ldots \ldots$ & 19,30 & 64,79 & 15,91 & $3.520,08$ & 15,24 \\
\hline $\begin{array}{lllllll}\text { Quart } & \ldots & \ldots & \ldots & \ldots & \ldots\end{array}$ & 11,69 & 71,63 & 16,68 & $3.460,38$ & 19,22 \\
\hline $\begin{array}{lllll}\text { Allboraya } & \ldots & \ldots & \ldots & \ldots\end{array}$ & 14,42 & 78,90 & 6,68 & $3.249,00$ & 21,10 \\
\hline Benimamet $\ldots \ldots \ldots \ldots$ & 20,76 & 63,41 & 15,83 & $3.175,33$ & 24,81 \\
\hline $\begin{array}{llllll}\text { Játiva } & \ldots & \ldots & \ldots & \ldots & \ldots\end{array}$ & 53,41 & 26,11 & 20,48 & $3.175,25$ & $+2,34$ \\
\hline $\begin{array}{ccccc}\text { Chirivella } & \ldots & \ldots & \ldots & \ldots\end{array}$ & 13,35 & 65,93 & 20,72 & $3.139,79$ & 20,39 \\
\hline $\begin{array}{lllllll}\text { Silla } & \ldots & \ldots & \ldots & \ldots & \ldots\end{array}$ & +.21 & 75,77 & 20,02 & 3.061 .38 & 14,72 \\
\hline $\begin{array}{lllll}\text { Paiporta } & \ldots & \ldots & \ldots & \ldots\end{array}$ & 5,55 & 79,08 & 15,37 & $3.026,63$ & 21,47 \\
\hline
\end{tabular}

FUENTE: AMV, Documentación Lonja, Caja $64_{2}$.

Frente a esta situación se encontraban los casos de Valencia, Gandía, Carcagente y Játiva. En los tres últimos las ventas se concentraban mayoritariamente, y de una forma significativa, en los meses altos de la cosecha (entre enero y mayo), mientras que en Valencia se distribuían de una forma bastante homogénea a lo largo de todo el año, no viéndose prácticamente afectada esta situación por la inclusión o no de la seda extranjera. En todo caso, la circunstancia aludida, junto con la elevada entidad media que alcanzaban las partidas, evidencia perfectamente la existencia de comportamientos de carácter especulativo que conviene analizar.

El caso de Gandía puede ser adoptado como ejemplo del comportamiento de los vendedores residentes en los pequeños núcleos urbanos algo alejados de la capital pero que, al hallarse ubicados en zonas con una elevada producción de materia prima sedera, se veían atraídos por la demanda del contraste. No en vano dicho lugar constituyó el tercer centro en importancia por el volumen de la seda comercializada, después de Valencia y la Particular Con- 
tribución. Como puede apreciarse en el cuadro 7, en el caso de Gandía existía también una elevada cantidad de pequeños vendedores que enajenaban can. tidades de seda muy reducidas. Casi la mitad de los existentes comercializaron volúmenes inferiores a 50 libras, representando sus ventas sólo el 3,36 por 100 del total. Otro 41 por 100 vendió cantidades comprendidas entre 50 y 500 libras, proporcionando cerca del 20 por 100 de la seda total. No obstante, frente a esta mayoría de pequeños o medianos vendedores se encontraban seis personas que enajenaron más de 500 libras y acapararon conjuntamente el 77,02 por 100 de la seda vendida por Gandia. ¿Quiénes eran éstos y cuál fue el ritmo con el que realizaron la comercialización? En el cuadro 8 se puede apreciar perfectamente que la estrategia de las ventas fue muy concordante en los cuatro primeros casos, quienes acaparaban más del 65 por 100 de la seda vendida por Gandía. En todos ellos se concentró más del 50 por 100 del volumen total comercializado en los meses altos de la cosecha, hasta el punto de que en dos casos se efectuaron entonces todas las ventas. No cabe duda, pues, que su comportamiento fue claramente especulativo, como puede revelar también la elevada entidad media que alcanzaban las partidas por ellos enajenadas. Afortunadamente, la identidad concreta de cuatro de estos seis principales vendedores hemos podido conocerla al aparecer en la relación de los mayores contribuyentes de la localidad en $1778^{19}$. Significativamente, el principal vendedor, Juan Sancho, que, por si solo, proporcionó cerca del 37 por 100 de la seda vendida por Gandía, era uno de los mayores comerciantes de este lugar. Lo mismo se puede decir de la viuda de Juan Sereis, mientras

\section{CUADRO 7}

Distribucion de los vendedores de seda residentes en Gandia

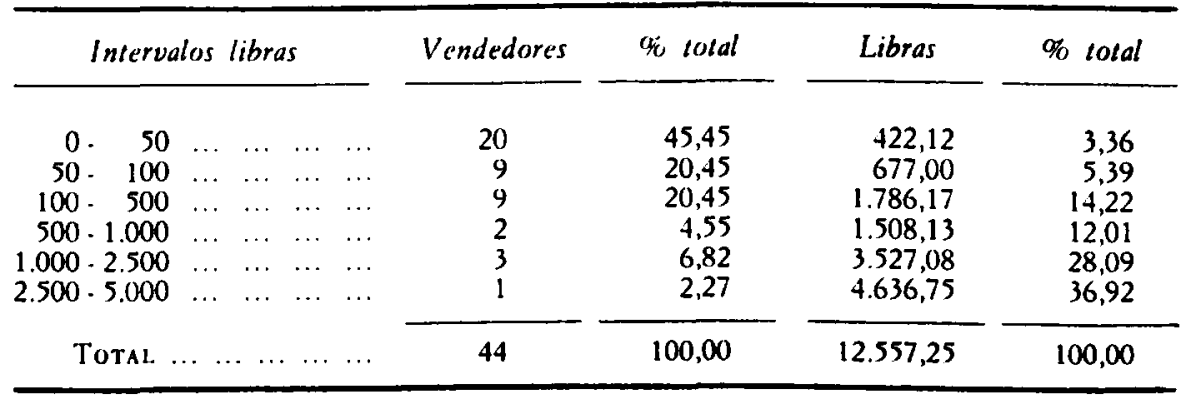

Fuente: AMV, Documentación Lonja, Caja $64_{2}$.

19 Morant (1984), pp. 168-171. 


\section{CUADRO 8}

Ritmo de enajenaciones de seda de los principales vendedores de Gandia (Datos en libras valencianas)

\begin{tabular}{|c|c|c|c|c|c|}
\hline \multirow[b]{2}{*}{ Venaiedores } & \multicolumn{3}{|c|}{ PORCENTAIES SOBRE TOTAL I.IBRAS } & \multirow[b]{2}{*}{$\begin{array}{l}\text { Total } \\
\text { libras }\end{array}$} & \multirow[b]{2}{*}{$\begin{array}{l}\text { Media } \\
\text { libras }\end{array}$} \\
\hline & $\begin{array}{l}\text { Enero- } \\
\text { mayo }\end{array}$ & $\begin{array}{l}\text { Junio- } \\
\text { agosto }\end{array}$ & $\begin{array}{l}\text { Septiembri } \\
\text { diciembre }\end{array}$ & & \\
\hline Sancho, Juan & 51,28 & 34,53 & 14,19 & $4.636,75$ & 105,38 \\
\hline Ros, Vicente $\ldots \ldots$. . & 100,00 & 0,00 & 0,00 & $1.466,80$ & 104,77 \\
\hline Sereis, Juan (vda.) ... & 60,72 & 39,28 & 0,00 & $1.035,34$ & 115,04 \\
\hline Company, Tomás ....... & 100,00 & 0,00 & 0,00 & $1.024,96$ & 68,33 \\
\hline Serna, Isidro ... ....... & 14,52 & 73,58 & 11,90 & 981,62 & 75,51 \\
\hline Manchón, Antonio .... & 25,91 & 26,53 & 47,56 & 526,51 & 87,75 \\
\hline
\end{tabular}

FUENTE: AMV, Documentación Lonja, Caja 64.

que Tomás Company aparecía como confitero. Por su parte, Isidro Serna, que era el único que concentraba la mayoría de sus ventas entre junio y agosto, era un torcedor, por lo que su comportamiento es perfectamente explicable (se limitaría a dar salida a la seda que torcía). Por tanto, en el caso de Gandía se aprecia perfectamente la existencia de un reducido grupo de grandes vendedores de seda que solían concentrar sus enajenaciones en los meses altos de la cosecha, cuando los precios de la materia prima alcanzaban sus niveles más elevados. Y, significativamente, la mayoría de ellos, más que grandes cosecheros, eran sobre todo comerciantes que podían estar enriqueciéndose por medio de estas prácticas de carácter especulativo.

De todas formas, no cabe duda que son los vendedores originarios de Valencia los que ofrecen el mayor interés, puesto que fueron ellos los que proporcionaron las cantidades más elevadas de seda vendida en el contraste. Pero, como ya se advirtió, cabe distinguir en este caso la seda autóctona de la extranjera, al suponer realidades bastante distintas. Con respecto a la seda autóctona, la distribución de los vendedores según su entidad (véase cuadro 9) presenta trazos algo similares a los que hemos visto en Gandía. Como allí, existía también una elevada proporción de pequeños vendedores que, representando más del 40 por 100 del total, sólo aportaban algo más del 3 por 100 de la seda comercializada. Había, igualmente, una nutrida capa intermedia de vendedores de entre 50 y 500 libras, que, en este caso. era algo más numerosa, al acercarse al 50 por 100 del total, y que acaparaba 
también una proporción de seda más elevada, del 36,97 por 100. Finalmente, el grupo superior acaparaba una proporción algo inferior a la de los que se encontraban en idéntica situación en Gandía, ascendiendo, de todas formas, al 59,23 por 100 . Lo más interesante, en todo caso, es analizar el comportamiento como vendedores de esta reducida minoría. En el cuadro 10 se ha plasmado esta circunstancia en el caso de los 17 principales vendedores que, conjuntamente, proporcionaron en torno al 40 por 100 de la seda no extranjera enajenada por los residentes en Valencia. Como puede apreciarse, la estrategia de las ventas es bastante desigual. Sorprendentemente, existió un grupo bastante nutrido que concentró la práctica totalidad de sus ventas en los meses inmediatos a la cosecha, adoptando el comportamiento que era habitual entre los pequeños vendedores. Sin embargo, resulta quizá significativo que en ninguno de los seis casos que así actuaron se tenga constancia de su posible intervención en actividades comerciales ${ }^{20}$. Todo parece indicar, pues, que se trataba de meros cosecheros que se limitaban a comercializar su producción. Por el contrario, no puede constituir una mera casualidad el hecho de que los tres vendedores que concentraron la práctica totalidad de sus operaciones en los meses altos de la cosecha fuesen grandes comerciantes. Se trataba de Josep Vaquer y Gregorio Torres, comerciantes de carácter diversificado que,

\section{CUADRO 9}

Distribución de los vendedores de seda no extranjera residentes en Valencia

\begin{tabular}{|c|c|c|c|c|}
\hline Intervalos libras & Vendedores & of total & Libras & $\%$ total \\
\hline $\begin{array}{rrrrrr}0 & 50 & \ldots & \ldots & \ldots & \ldots \\
50- & 100 & \ldots & \ldots & \ldots & \ldots \\
100- & 500 & \ldots & \ldots & \ldots & \ldots \\
500-1.000 & \ldots & \ldots & \ldots & \ldots \\
1.000- & 2.500 & \ldots & \ldots & \ldots & \ldots \\
2.500 & 10.000 & \ldots & \ldots & \ldots & \ldots\end{array}$ & $\begin{array}{r}172 \\
75 \\
118 \\
25 \\
14 \\
3\end{array}$ & $\begin{array}{r}42,26 \\
18,43 \\
28,99 \\
6,14 \\
3,44 \\
0,74\end{array}$ & $\begin{array}{r}3.299,63 \\
5.365,85 \\
26.770,67 \\
16.745,54 \\
19.794,50 \\
14.954,25\end{array}$ & $\begin{array}{r}3,80 \\
6,17 \\
30,80 \\
19,26 \\
22,77 \\
17,20\end{array}$ \\
\hline $\begin{array}{lllllll}\text { TOTAL } & \ldots & \ldots & \ldots & \ldots & \ldots\end{array}$ & 407 & 100,00 & $86.930,44$ & 100,00 \\
\hline
\end{tabular}

Fuente: AMV, Documentación Lonja, Caja $64_{2}$.

* Ninguna de las seis personas aludidas aparece en la relación de individuos que efectuaban actividades comerciales (ya fuese como profesión o de forma ocasional) que fue confeccionada en 1805 y que es la más completa que se ha localizado a fines del Antiguo Régimen. AMV, Documentación Lonja, Caja 41, Exp. núm. 7. No obstante, cabe señalar que en la distribución de la cuota asignada al comercio de Valencia en el subsidio extraordinario del año 1800 sí que consta un Vicente Esparza en la categoría 27:", una de las más bajas. AMV, Documentación Lonja, Caja $36_{3}$. 


\title{
CUADRO 10
}

\author{
Ritmo de enajenaciones de seda no exiranjera de los principales \\ vendedores de Valencia \\ (Datos en libras valencianas)
}

\begin{tabular}{|c|c|c|c|c|c|}
\hline \multirow[b]{2}{*}{ Vendedores } & \multicolumn{3}{|c|}{ PORCENTAIES SOBRE TOTAL LIBRAS } & \multirow[b]{2}{*}{$\begin{array}{l}\text { Total } \\
\text { libras }\end{array}$} & \multirow[b]{2}{*}{$\begin{array}{l}\text { Media } \\
\text { libras }\end{array}$} \\
\hline & $\begin{array}{l}\text { Enero } \\
\text { mayo }\end{array}$ & $\begin{array}{l}\text { Junio. } \\
\text { agosto }\end{array}$ & $\begin{array}{l}\text { Septiembre- } \\
\text { diciembre }\end{array}$ & & \\
\hline Esparza Vicente ... ... & 0,16 & 92,11 & 7,73 & $8.977,08$ & 280,53 \\
\hline Vaquer, Josep $\ldots . . . . . .$. & 91,34 & 8,66 & 0,00 & $3.236,00$ & 101,13 \\
\hline Nogues, Antonio ... ... & 30,71 & 44,70 & 24,59 & $2.741,17$ & 171,32 \\
\hline Minguet, Josep $\ldots$... & 0,00 & 100,00 & 0,00 & $2.030,33$ & 290,05 \\
\hline Torres, Gregorio ... ... & 92,80 & 7,20 & 0,00 & $1.820,42$ & 107,08 \\
\hline Pastor, Ignacio . . . . . . & 0,00 & 0,00 & 100,00 & $1.659,33$ & 553,11 \\
\hline Alcina, Manuel ....... & 71,31 & 0,00 & 28,69 & $1.551,00$ & 172,33 \\
\hline Tello, Antonio ....... & 1,81 & 98,19 & 0,00 & $1.522,04$ & 190,26 \\
\hline Ferrer, Melchor ...... & 100,00 & 0,00 & 0,00 & $1.444,33$ & 131,30 \\
\hline Motas, Roque $\ldots . .$. & 0,00 & 88,75 & 11,25 & $1.375,25$ & 171,91 \\
\hline Caro, Fernando ... ... & 32,33 & 19,07 & 48,60 & $1.347,42$ & 149,71 \\
\hline Gil, Francisco $\ldots \ldots \ldots$ & 6,03 & 87,97 & 6,00 & $1.327,38$ & 102,11 \\
\hline David, Juan $\ldots$... & 0,00 & 0,00 & 100,00 & $1.279,42$ & 255,88 \\
\hline Alapont, Manuel ... ... & 45,99 & 21,47 & 32,54 & $1.149,17$ & 88,40 \\
\hline Sagrista, Pascual ... ... & 36,80 & 14,43 & 48,77 & $1.143,67$ & 127,07 \\
\hline Pastor e Hijo (vda.) ... & 0,00 & 0,00 & 100,00 & $1.126,50$ & $1.126,50$ \\
\hline Sanchis, Juan ......... & 0,00 & 98,38 & 1,62 & $1.018,25$ & 101,83 \\
\hline
\end{tabular}

Fuente: AMV, Documentación Lonja, Caja 64.

según el Almanak Mercantil de 1804, se hallaban especializados en el comercio con Cataluña y que fueron encuadrados en el reparto del subsidio extraordinario de 1800 en las categorías $8 .^{a}$ y $16 .^{2}$, respectivamente, y de Melchor Ferrer, uno de los comerciantes de carácter diversificado más enriquecidos

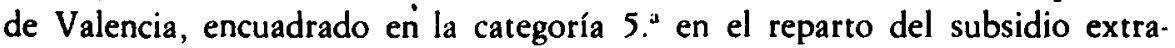
ordinario aludido ${ }^{21}$. Por tanto, el análisis del comportamiento de los principales vendedores de seda no extranjera de Valencia parece corroborar la idea, ya apuntada en el caso de Gandía, de que eran los comerciantes los que actuaban con unos objetivos más claramente especulativos, aunque permite comprobar también que no se puede identificar de una forma lineal a los grandes vendedores con los especuladores.

"Sobre la distribución del subsidio extraordinario del año 1800 entre el comercio de la ciudad de Valencia y la significación de las diversas categorías, véase Franch (1986), pp. 141-154. 
CUADRO 11

Distribución de los vendedores de seda extranjera

\begin{tabular}{|c|c|c|c|c|}
\hline Intervalos libras & Vendedores & $0 \%$ tolal & Libras & \% total \\
\hline $\begin{array}{rrrrrr}0 & 50 & \ldots & \ldots & \ldots & \ldots \\
50 \cdot & 500 & \ldots & \ldots & \ldots & \ldots \\
500 \cdot & 5.000 & \ldots & \ldots & \ldots & \ldots \\
5.000 & 35.000 & \ldots & \ldots & \ldots & \ldots\end{array}$ & $\begin{array}{r}2 \\
32 \\
27 \\
9\end{array}$ & $\begin{array}{r}2,86 \\
45,71 \\
38,57 \\
12,86\end{array}$ & $\begin{array}{r}22,58 \\
6.198,36 \\
33.583,74 \\
100.952,97\end{array}$ & $\begin{array}{r}0,02 \\
4,40 \\
23,86 \\
71,72\end{array}$ \\
\hline TOTAL $\ldots \ldots \ldots \ldots$ & 70 & 100,00 & $140.757,66$ & 100,00 \\
\hline
\end{tabular}

Fuente: AMV, Documentación Lonja, Caja 642.

Como ya se ha indicado, la comercialización de la seda de origen extranjero presentaba unas características propias que conviene analizar. En principio, cabe destacar que el ritmo con el que aquélla se producía era muy distinto al que aparecía en el caso de la seda autóctona, dando lugar a una evidente atenuación de la estacionalidad. En el año 1796, por ejemplo, el 34,92 por 100 de la seda extranjera se vendió entre enero y mayo; el 36,38 por 100 , entre junio y agosto; y el 28,69 por 100 , entre septiembre y di. ciembre. Es una lástima que la mayoría de los años en que disponemos de referencias sobre la seda extranjera vendida en el contraste se vieran afectados por las crisis comerciales derivadas de los continuos conflictos bélicos de fines del siglo xvill y principios del xIx. De todas formas, cuando el bloqueo no impidió la afluencia de cantidades significativas, se aprecia perfectamente la cierta homogeneidad a lo largo del año con que se producian sus ventas. Es decir, todo parece indicar que la continua importación de seda extranjera hubiera podido contribuir a superar la estacionalidad que, como veremos, acababa afectando a la dinámica de la propia sedería.

Con respecto a los vendedores de seda extranjera, una somera distribución atendiendo a su entidad nos revela una situación muy distinta a la que hemos visto en los casos anteriores. Como se puede apreciar en el cuadro 11, los pequeños vendedores de menos de 50 libras son prácticamente inexistentes. Los medianos, de entre 50 y 500 libras, representan un grupo ya numeroso, que se acerca a la mitad del total, pero sólo acaparan el 4,40 por 100 de la seda vendida. Por tanto, lo realmente destacable es la concentración de las ventas que se da en los grandes vendedores. Es el 51,43 por 100 de los ven. dedores que enajenan más de 500 libras los que aportan el 95,58 por 100 de la seda extranjera comercializada en el contraste. $Y$ de este grupo aún 
sobresalen los nuevo vendtdores de más de 5.000 libras, que, por sí solos, acaparan el 71,72 por 100 de la seda vendida. La elevada concentración del negocio en manos de esta reducida minoría constituye, pues, el rasgo principal que diferencia a este colectivo de los casos anteriores. ¿Quiénes eran los que controlaban esta actividad? En este sector no cabe duda del dominio absoluto ejercido por los comerciantes: ocho de los nueve principales vendedores (véase cuadro 12) lo eran con toda seguridad, y sólo en el caso de la viuda de Olivert no se ha logrado constatar su vinculación con el comercio. Por lo demás, cabe destacar en este aspecto el papel ejercido por los comerciantes de origen genovés. Esta ascendencia tenía Josep Batifora ${ }^{22}$, el principal vendedor de seda extranjera, quien, por sí solo, enajenó algo más de la quinta parte de la cantidad total comercializada. Y de la misma procedencia eran Bernardo Ferraro, Juan Bautista Bensi y Agustín Vila. No debemos de extrañarnos de este predominio genovés, teniendo en cuenta que la seda importada solía proceder del norte de Italia. Aparte de los genoveses, destacaban también entre los principales vendedores los comerciantes muy relacionados con el tráfico con Cataluña. A esta actividad se dedicaban, como hemos podido ver, Josep Vaquer y Gregorio Torres, y todo parece indicar que Joaquín Solernou se orientaba también en la misma línea. Quizá esta presencia de comer. ciantes relacionados con el comercio catalán se derive de la canalización de

\section{CUADRO 12}

Ritmo de enajenaciones de seda extranjera por los principales vendedores

\begin{tabular}{|c|c|c|c|c|c|}
\hline \multirow[b]{2}{*}{ Vendedores } & \multicolumn{3}{|c|}{ PORCENTAJES SOBRE TOTAL LIBRAS } & \multirow[b]{2}{*}{$\begin{array}{l}\text { Tolal } \\
\text { libras }\end{array}$} & \multirow[b]{2}{*}{$\begin{array}{l}\text { Media } \\
\text { libras }\end{array}$} \\
\hline & $\begin{array}{l}\text { Enero- } \\
\text { mayo }\end{array}$ & $\begin{array}{l}\text { Junio- } \\
\text { ugosto }\end{array}$ & $\begin{array}{l}\text { Septicmbre- } \\
\text { diciembre }\end{array}$ & & \\
\hline Batifora, Josep ....... & 40,18 & 48,62 & 11,20 & $31.781,83$ & 153,54 \\
\hline Vaquer, Josep ........... & 23,08 & 28,36 & 48,56 & $17.593,17$ & 161,41 \\
\hline Ferraro, Bernardo ........ & 39,22 & 25,95 & 34,83 & $11.241,40$ & 144,12 \\
\hline Torres, Gregorio ... ... & 60,45 & 22,27 & 17,28 & $9.966,25$ & 142,37 \\
\hline Bensi, Juan Bta. ... ... & 55.11 & 26,80 & 18,09 & $7.150,58$ & 158,90 \\
\hline Ximénez del Río, M. ... & 30,65 & 30,75 & 38,60 & $6.252,67$ & 168,99 \\
\hline Olivert (vda.) $\ldots \ldots \ldots \ldots$ & 33,78 & 37,87 & 28,34 & $6.078,25$ & 155,85 \\
\hline Solernou, Joaquín . ... & 0,00 & 52,94 & 47,06 & $5,495,08$ & 148,52 \\
\hline Vila, Agustín ............ & 83,98 & 10,50 & 5,51 & $5.393,74$ & 199,77 \\
\hline
\end{tabular}

FuENTE: AMV, Documentación Lonja, Caja 64.

"Sobre los origenes de esta dinastía comercial, véase Franch (1984). 
buena parte de las importaciones a través del puerto de Barcelona, teniendo en cuenta, como ya se ha indicado antes, que la cantidad de seda extranjera vendida en el contraste en 1796 fue mucho más elevada que la que constaba que se habia importado directamente por el puerto de Valencia.

Finalmente, el ritmo de las ventas de la seda extranjera era muy distinto también al que se ha visto en los casos anteriores. Como puede apreciarse en el cuadro 12, los nueve principales vendedores tendían a distribuir sus operaciones a lo largo de todo el año, favoreciendo con ello que a nivel global se produjese esa tendencia a la carencia de estacionalidad que se ha comentado. De todas formas, en algunos casos se aprecia perfectamente la tendencia a concentrar las operaciones en los meses altos de la cosecha (caso de Juan Bautista Bensi, Gregorio Torres o, sobre todo, Agustín Vila), mientras que, por el contrario, sólo uno de los principales vendedores enajenó más del 50 por 100 del volumen total de sus ventas en los meses inmediatamente posteriores a la cosecha.

En conjunto, pues, las ventas de seda realizadas en el contraste en 1796 revelan perfectamente la irradiación que alcanzaba el mercado de la ciudad de Valencia. Esta se extendía a lo largo de toda la extensión del antiguo Reino, pero era mucho más intensa en las áreas rurales próximas. De ellas afluían hacia el contraste en los meses inmediatos a la cosecha una multitud de pequeños campesinos que enajenaban rápidamente su reducida producción con el fin de atender a sus urgencias económicas. En cambio, en los pequeños núcleos urbanos algo más alejados de la capital pero ubicados en zonas con una elevada producción de seda, junto a los comportamientos de este tipo, aparecían claramente prácticas de carácter especulativo que, según ha revelado el caso de Gandía, parecían estar relacionadas con las actividades realizadas por los comerciantes. Algo similar se deduce del comportamiento de los vendedores de seda no extranjera residentes en Valencia, aunque introduciendo la matización de que algunos grandes vendedores (debido, quizá, a su poca relación con el mundo comercial) actuaban de forma idéntica a la de los pequeños campesinos. Finalmente, eran también los comerciantes los que dominaban la comercialización de la seda extranjera, una comercialización que se extendía a lo largo de todo el año de una forma bastante homogénea. De todo ello podría deducirse, en fin, que eran básicamente los comerciantes, más que los grandes cosecheros, los que parecian beneficiarse del alza de precios que provocaba la escasez de materia prima en los meses altos de la cosecha. 


\section{IV) Los compradores de seda}

A diferencia de la gran multitud de vendedores, cuya cifra exagerada impide un tratamiento de conjunto, los compradores que adquirieron seda en el contraste en 1796, con ser una cantidad elevada, pueden ser analizados globalmente. Teniendo en cuenta, como ya se ha indicado, que en la ciudad de Valencia se concentraba la práctica totalidad de la manufactura sedera del País Valenciano y que ésta tenía en el contraste el centro fundamental de abastecimiento, su estudio ofrece un indudable interés.

Atendiendo a la entidad de sus adquisiciones, los 711 compradores que constan en el registro de 1796 se distribuían de la forma que aparece en el cuadro 13. (como puede verse en él, existía también en este caso una gran cantidad de pequeños compradores, hasta el punto de que cerca de la mitad del total adquirían menos de 100 libras de seda. Hay que tener en cuenta que esta cifra era insuficiente para mantener en funcionamiento durante todo el año un telar ancho de seda. La cantidad requerida para ello no se conoce exactamente, al constituir el núcleo esencial de la polémica que mantenían los cosecheros y exportadores con los fabricantes. En todo caso, oscilaba entre un mínimo de 120 libras, que defendían aquéllos, y un máximo de 200 libras, en que insistían éstos ${ }^{23}$. Por tanto, la elevada cifra que suponían aque. llos pequeños compradores sólo puede deberse a la acción de los cordoneros. fabricantes de medias, miembros del arte menor, etc., quienes requerían pequeñas cantidades de seda para elaborar sus productos. Incluso entre ellos cabría incluir también a algunos torcedores que adquirían seda en bruto para venderla después de haberla torcido. En todo caso, las compras realizadas por este elevado contingente de personas no llegaban a suponer más que el 2,37 por 100 de la cantidad total comercializada en el contraste. El escalón superior a este grupo debían de constituirlo ese 28,83 por 100 de compradores que adquirian entre 100 500 libras de seda. Se trataba de cifras ya casi suficientes en su limite inferior para mantener en funcionamiento un telar ancho de seda durante todo el año. Aquí podia encontrarse, pues, todo el artesanado sedero que aún había logrado mantener su independencia. De la debilidad de su papel puede ser revelador el hecho de que la proporción de seda que adquirieron (10,06 por 100) fuese muy inferior al porcentaje que ellos representaban sobre el total de compradores (28,83 por 100). Esta circunstancia comienza a desaparecer a partir del nivel superior, que, seguramente, marcaría la frontera entre el artesanado independiente y el empresariado sedero. Sin embargo, dentro de este último grupo aún cabría introducir

2" Véase Martínez Santos (1981), p. 56. La cifra de 200 libras fue asumida también por la Junta de Comercio de Valencia en sus informes de la segunda mitad del siglo xviII. Véase Franch (1989), p. 66. 
una diferencia entre los pequeños y los grandes empresarios sederos. Aquéllos podrían estar constituidos por los 133 compradores que adquirían entre 500 y 2.500 libras. Representando el 18,71 por 100 del total, las compras efectuadas por este colectivo ya suponían una proporción superior a la constituida por ellos, al elevarse hasta el 29,22 por 100 de la materia prima comercializada. Sin embargo, este desequilibrio se acentuaba entre los que se puede considerar como los grandes empresarios sederos. En efecto, los 50 compradores de más de 2.500 libras representaban sólo el 7,03 por 100 del total, pero, en cambio, adquirieron más de la mitad de la materia prima comercializada en el contraste, concretamente el 58,36 por 100. No cabe duda, pues, que éstos constituyeron la oligarquía sedera más importante, por lo que merecen un análisis más detenido.

\section{CUADRO 13}

Distribución de los compradores de seda en el contraste en el año 1796 (Datos en libras valencianas)

\begin{tabular}{|c|c|c|c|c|}
\hline Intervalos libras & Compradores & 90 total & Libras & $\%$ total \\
\hline $\begin{array}{rrrrrr}0 . & 50 & \ldots & \ldots & \ldots & \ldots \\
50 \cdot & 100 & \ldots & \ldots & \ldots & \ldots \\
100 \cdot & 500 & \ldots & \ldots & \ldots & \ldots \\
500 \cdot & 1.000 & \ldots & \ldots & \ldots & \ldots \\
1.000 \cdot & 2.500 & \ldots & \ldots & \ldots & \ldots \\
2.500 \cdot & 5.000 & \ldots & \ldots & \ldots & \ldots \\
5.000 \cdot 10.000 & \ldots & \ldots & \ldots & \ldots \\
10.000 \cdot & 25.000 & \ldots & \ldots & \ldots & \ldots \\
10.000\end{array}$ & $\begin{array}{r}225 \\
98 \\
205 \\
76 \\
57 \\
28 \\
17 \\
5\end{array}$ & $\begin{array}{r}31,65 \\
13,78 \\
28,83 \\
10,69 \\
8,02 \\
3,94 \\
2,39 \\
0,70\end{array}$ & $\begin{array}{r}4.797,35 \\
6.924,42 \\
49.721,63 \\
54.682,92 \\
89.775,88 \\
100.541,46 \\
115.664,86 \\
72.253,08\end{array}$ & $\begin{array}{r}0,97 \\
1,40 \\
10,06 \\
11,06 \\
18,16 \\
20,34 \\
23,40 \\
14,62\end{array}$ \\
\hline TOTAL $\ldots \ldots \ldots \ldots$ & 711 & 100,00 & $494.361,59$ & 100,00 \\
\hline
\end{tabular}

Fuente: AMV, Documentación Lonja, Caja $64_{2}$.

La localización de los miembros de esta minoría de grandes empresarios sederos no ha deparado grandes sorpresas, puesto que la imagen resultante es bastante coincidente con la información proporcionada por las fuentes fiscales de la época. Quizá lo que deba subrayarse, por ello, es la validez que puede atribuirse a ambos tipos de documentación (la del contraste y la fiscal), ya que el entrecruzamiento de sus datos ha proporcionado unos resultados totalmente coherentes. En su día ya se indicó que la mejor fuente para estudiar la situación de la burguesía comercial valenciana de fines del siglo xvirI era 
el reparto de la cuota asignada al comercio de la ciudad de Valencia en el subsidio extraordinario de 1800 . La escrupulosidad con la que la Junta de Comercio de Valencia ejecutó esta tarea otorgaba a sus datos unas ciertas garantías, que se veían reforzadas por la coincidencia con la información obtenida en muchos casos a través de la documentación notarial ${ }^{24}$. Ahora cabe añadir a estos supuestos de fiabilidad el espaldarazo que supone el hecho de que los comerciantes sederos más enriquecidos que allí aparecían constituyan también los principales compradores de seda, según se deriva de los registros del contraste de 1796. En efecto, entre los 39 principales contribuyentes que aportaron casi la mitad de la cuota asignada al comercio de Valencia, el grupo más numeroso lo constituían los comerciantes-fabricantes de tejidos de seda, con 17 miembros. Pues bien, 14 de éstos se encuentran entre los 22 principales compradores de más de 5.000 libras de seda que adquirieron el 38,02 por 100 de la materia prima enajenada en el contraste en 1796. La correspondencia es más perfecta, si cabe, entre los primeros compradores. Como se puede apreciar en el cuadro 14, ahora ya no debe caber la más mínima duda de que el principal empresario sedero de fines del siglo xvill fue Félix Pastor, quien acabó convirtiéndose en el flamante marqués de San Joaquín y Pastor al ennoblecerse ${ }^{25}$. En el reparto del subsidio de 1800 aparecía como la persona física más acaudalada del comercio de la ciudad. De su entidad como fabricante ya se conocían algunos datos gracias al «alarde publicitario» que realizó para preparar su ennoblecimiento. Según él, en 1776 daba ocupación a 148 telares, cantidad que se había elevado a 174 en 1798. Partiendo de un consumo medio anual por telar de 120 libras, Martínez Santos calculaba que Pastor debería haber necesitado la adquisición de entre 17.000 y 20.000 libras de seda ${ }^{26}$. Según el registro del contraste de 1796 , la cifra se elevó realmente en este año a cerca de 25.000 libras. Para calibrar la importancia de esta cantidad podría tenerse en cuenta, por ejemplo, que la inversión requerida para su adquisición (a un precio medio de unos 40 reales valencianos la libra) rondaría las 100.000 libras (moneda), lo que constituía una auténtica fortuna que pocos comerciantes lograban reunir. Igualmente, las compras de Félix Pastor representaban, por sí solas, algo más del 5 por 100 de la seda total comercializada en el contraste en 1796, y doblaban casi la cantidad adquirida por el segundo comprador en importancia. En este caso se trataba de Domingo Ortiz, miembro de la sociedad «Viuda de Vivanco y Ortiz», y que segura-

\footnotetext{
24 Sobre la distribución de la cuota asignada al comercio de Valencia en el subsidio extraordinario de 1800 y la información que proporciona sobre la burguesía comercial valenciana, véase Franch (1986), pp. 134-154.

${ }^{25}$ Un tratamiento en profundidad de su proceso de ennoblecimiento se encuentra en R. Franch (1989 b), pp. 92-107.

${ }^{26}$ Martínez Santos (1981), pp. 160-161.
} 
mente actuaría por cuenta de ella. Esta compañía fue encuadrada en el subsidio de 1800 en la misma categoría que Félix Pastor, por lo que su calidad de gran empresario sedero queda también corroborada. En fin, lo mismo se puede decir de los otros 12 grandes empresarios sederos que en el subsidio de 1800 aparecían en las siete primeras categorías (Oliag, Valls, Tamarit, Pasqual, Carra, Camps, Orellana, etc.). De los tres restantes que figuraban allí y no aparecen entre los 22 principales compradores cabe citar el caso de la dinastía de los Canet ${ }^{27}$, ya que dos de sus miembros, Estanislao y Mariano, adquirieron individualmente un total de $7.334,17$ libras de seda, mientras que el apellido

\section{CUADRO 14}

Ritmo de adquisiciones de los principales compradores de seda en el contraste en el año 1796

(Datos en libras valencianas)

\begin{tabular}{|c|c|c|c|c|c|}
\hline \multirow[b]{2}{*}{ Compradores } & \multicolumn{3}{|c|}{ PORCENTAJES SOBRE TOTAL LIBRAS } & \multirow[b]{2}{*}{$\begin{array}{l}\text { Total } \\
\text { libras }\end{array}$} & \multirow[b]{2}{*}{$\begin{array}{l}\text { Media } \\
\text { libras }\end{array}$} \\
\hline & $\begin{array}{l}\text { Enero- } \\
\text { mayo }\end{array}$ & $\begin{array}{l}\text { Junio- } \\
\text { agosto }\end{array}$ & $\begin{array}{l}\text { Septiembre- } \\
\text { diciembre }\end{array}$ & & \\
\hline Pastor Félix & 9.06 & 60.79 & 30,15 & $24.901,21$ & 47,16 \\
\hline Ortiz, Domingo ... ... & 3,27 & 85,58 & 11,15 & $13.886,50$ & 27,72 \\
\hline Oliag Hermanos $\ldots \ldots$ & 28,92 & 50,80 & 20,27 & $12.319,17$ & 42,77 \\
\hline Valls, Tomás ... & 27,14 & 47,50 & 25,36 & $10.672,83$ & 54,18 \\
\hline Tamarit, Vicente ... & 12,14 & 73,42 & 14,45 & $10.473,38$ & 24,64 \\
\hline Pasqual, Francisco R. & 29,90 & 39,72 & 30,38 & $9.285,08$ & 77,38 \\
\hline Ruix, Ramón ... ....... & 39,53 & 29,73 & 30,74 & $9.032,21$ & 67,40 \\
\hline Carra, Vicente . ... ... & 28,39 & 61,63 & 9,98 & $8.669,58$ & 27,09 \\
\hline Camps, Josep ... & 10,25 & 89,09 & 0,66 & $7.366,67$ & 27,39 \\
\hline Arias, Antonio P. ...... & 22,04 & 41,62 & 36,34 & $7.205,88$ & 51,11 \\
\hline Real Fábrica $\ldots \ldots \ldots$ & 0,00 & 73,17 & 26,83 & $6.986,46$ & 40,38 \\
\hline Orellana, Juan Bta. ... & 14,53 & 74,30 & 11,18 & $6.720,96$ & 35,75 \\
\hline Peribáñez, Josep . . . ... & 22,88 & 44,24 & 32,88 & $6.719,04$ & 41,99 \\
\hline Mustieles, Roque $\ldots \ldots$ & 39,88 & 36,78 & 23,33 & $6.572,33$ & 37,13 \\
\hline Pastor, Josep $\ldots \ldots \ldots$ & 30,46 & 50,64 & 18,90 & $6.398,04$ & 35,54 \\
\hline Espinosa, Mariano . ... & 31,16 & 52,47 & 16,36 & $6.370,46$ & 49,77 \\
\hline Ruiz, Vicente ... ... & 37,05 & 41,94 & 21,01 & $6.357,58$ & 81,51 \\
\hline Domínguez, Tomás & 15,24 & 78,82 & 5,94 & $6.119,83$ & 32,38 \\
\hline Iranzo, Carlos $\ldots \ldots \ldots \ldots$ & 33,84 & 64,33 & 1,83 & $6.028,58$ & 47,47 \\
\hline Vidal, Francisco ... & 57,03 & 29,45 & 13,52 & $5.449,00$ & 78,97 \\
\hline Belenguer, Vicente & 15,12 & 81,96 & 2,92 & $5.321,98$ & 35,01 \\
\hline Maciá, Vicente . ... & 34,96 & 50,89 & 14,15 & $5.061,17$ & 34,43 \\
\hline
\end{tabular}

Fuente: AMV, Documentación Lonja, Caja $64_{2}$.

${ }^{27}$ Sobre los orígenes de esta dinastía, véase $\mathrm{R}$. Franch (1989 b), pp. 65.72. Sobre sus actividades a finales del siglo xvin, véase Ardit (1985). 
"Canet", sin más especificaciones, aparece como comprador de otras 2.836 libras. No se puede sostener con rotundidad que el conjunto de estas adquisiciones se destinasen a sostener la actividad de la sociedad «Viuda de Mariano Canet e Hijos", pero cabe constatar que, si así fuese, ésta constituiría también uno de los compradores más importantes, superando ligeramente las 10.000 libras de seda. Finalmente, los otros dos sederos que figuraban entre los prin. cipales contribuyentes en 1800 eran Alexos Camporrey, que en 1796 adquirió 4.007 libras de seda, y Roque Escoto, que compró 3.297 libras.

No obstante, entre los 22 principales compradores de seda de 1796 aparecían ocho personas que se situaron en las categorías intermedias en el reparto del subsidio de 1800 . Se trataba de Josep Pastor (hermano de Félix y de Josep Peribáñez, que figuraban en la 12:"; Tomás Domínguez, encuadrado en la 13."; Francisco Vidal, en la 17."; Vicente Maciá, en la 19."; Roque Mustieles, en la 22.a : y de Antonio Pasqual de Arias y Vicente Ruiz, que no figuraban.

Por lo demás, y como resulta lógico, la práctica totalidad de estos 22 principales compradores de 1796 fueron incluidos en la relación de comerciantes confeccionada en el año 1805 como comerciantes-fabricantes al por mayor de tejidos de seda ${ }^{2 k}$. Sólo uno de aquéllos (Antonio Pasqual de Arias) no figura en dicha relación, mientras que Roque Mustieles era encuadrado entre los torcedores de seda, y Vicente Ruiz aparecia entre los «caudalistas».

La situación es más compleja si se procede al análisis del resto del grupo que habíamos incluido entre los grandes empresarios sederos, es decir, los 28 compradores que en 1796 adquirieron entre 2.500 y 5.000 libras de seda. Aquí la mayoría de sus miembros fueron encuadrados en las categorías intermedias ( $\mathrm{y}$ algunos incluso en las inferiores) en el reparto del subsidio de 1800, o bien no aparecieron en él. Las únicas excepciones las constituyen los casos aludidos de los Canet, Camporrey y Escoto, a los que cabe añadir la sociedad de la viuda de Lasala y a Josep Batifora, grandes comerciantes que desarrollaban un tráfico diversificado, ya que todos ellos se situaron en las categorías más elevadas. Igualmente, la actividad-marco en la que fueron encuadrados esos 28 compradores en la relación de 1805 es también más diversa. Los comerciantes-fabricantes de tejidos de seda aún constituian el contingente más numeroso, con nueve compradores; pero, junto a ellos, aparecían también cinco «caudalistas», tres comerciantes mayoristas que efectuaban un tráfico diversificado, tres torcedores, un propietario de tiendas de tejidos de seda, y siete que no se han localizado. Es decir, en este nivel los comerciantes al

2* En la relación de 1805 se incluían 125 comerciantes o razones sociales que efectuaban su tráfico al por mayor, de los cuales 62 se dedicaban al comercio de tejidos de seda y 63 desarrollaban una actividad de carácter diversificado. Véase Franch (1986), pp. 139.140. 
por mayor especializados en la producción y el tráfico de los tejidos de seda perdian ese práctico monopolio que ostentaban entre los 22 principales compradores. Junto a ellos comenzaban a aparecer ahora comerciantes que tenían a la sedería como uno más de sus múltiples negocios; personas que no se dedicaban realmente al comercio pero que tenían capitales invertidos en la fábrica; etc. Lógicamente, la identificación que este tipo de compradores tenía con el destino de la sedería era mucho menor que en aquellos casos.

Aparte de corroborar el predominio de la burguesía mercantil sedera más enriquecida entre los principales compradores, el análisis de éstos permite también confirmar el control de la sedería por los empresarios de origen autóctono o, en todo caso, nacional. Este fenómeno ya se puso de manifiesto al comprobar que sólo cuatro de los 62 comerciantes o razones sociales que aparecían en la relación de 1805 como comerciantes al por mayor de tejidos de seda eran de origen extranjero ${ }^{24}$. Ahora se puede añadir a esta circunstan. cia el hecho de que ninguno de los 22 principales compradores de seda en el contraste hubiese nacido fuera de España. Sólo en el grupo de los 28 compradores que adquirieron entre 2.500 y 5.000 libras de seda comienzan a aparecer empresarios extranjeros, pero limitándose su entidad a tres genoveses y dos franceses, y habiendo residido la mayoría de ellos tanto tiempo en España que sólo atendiendo a sus raíces más lejanas se les podía considerar como extranjeros ${ }^{30}$. Por tanto, la impresión, tantas veces repetida, de que la fábrica parecía estar dominada por elementos de origen foráneo ${ }^{31}$ carece de auténtico respaldo documental, al menos reniendo en cuenta la relación de los comerciantes-fabricantes al por mayor especializados en ella y la identidad de los principales compradores de seda en el contraste a fines del siglo xvin.

Finalmente, otra cuestión que cabe abordar es el ritmo con el que se efectuaban las compras, con el fin de averiguar si la estacionalidad con la que se producia la comercialización de la materia prima acababa repercutiendo en la propia dinámica de la sedería. Un somero análisis del cuadro 14 , en el que se ha reflejado aquel factor en el caso de los 22 principales compradores, parece inducir en dicho sentido. En efecto, 14 de los 22 principales compradores (es decir, casi los dos tercios de éstos) efectuaron más del 50 por 100 de sus adquisiciones totales anuales en el trimestre comprendido entre junio y agosto. No en vano la media adquirida durante este trimestre por los 22

Franch (1986), pp. 150-151.

" Se trataba de Domingo Francisco Ansaldo, Roque Escoto y Josep Batifora, de origen genovés, y de Juan Bautista Meybiele y la sociedad de la viuda de Lasala, de origen francés.

"Esta impresión fue rccogida también por Martínez Santos, quien llegó a apuntar la posibilidad de que los motines antifranceses de 1793 se derivasen de la influencia que las personas de esta nacionalidad ejercian sobre la sedería, pudiendo constituir, por tanto, una mera represalia. Martínez Santos (1981), p. 127. 
principales compradores se situaba en el 57,22 por 100. La concentración de las compras de la materia prima en los meses inmediatos a la cosecha constituía, pues, un fenómeno bastante común entre los principales empresarios sederos. La situación puede ilustrarse mejor examinando el ritmo mensual de las adquisiciones en los casos más importantes. Así, por ejemplo, Félix Pastor compró nada menos que 10.629,38 libras de seda sólo en el mes de junio de 1796 , lo que representaba el 42,68 por 100 de sus adquisiciones anuales. Posteriormente, sus compras rondaron entre las 1.000 y las 2.000 libras mensuales entre julio y diciembre, mientras que entre enero y mayo nunca había llegado a las 600 libras mensuales. Por su parte, Domingo Ortiz adquirió $9.136,46$ libras sólo en el mes de julio, lo que, unidas a las $2.036,13$ libras compradas en junio, suponía la concentración del 80,45 por 100 de las adquisiciones anuales en estos dos meses. Lógicamente, en los restantes meses del año sus compras nunca superaron las 1.000 libras. Y, significativamente, no realizó ninguna adquisición entre febrero y mayo. En fin, situaciones similares a éstas, aunque con distintos grados de concentración, se daban en las adquisiciones realizadas por los 22 principales compradores. Siempre las cantidades mensuales adquiridas se cifraban en millares en los meses inmediatos a la cosecha, mientras que, por el contrario, sólo suponían unos cen. tenares de libras o no existían en los cinco meses anteriores a aquélla. La única excepción a esta tónica la constituye el caso de Francisco Vidal, que concentró el 57,03 por 100 de sus adquisiciones entre enero y mayo, situándose la cifra más elevada de todo el año en el mes de abril. Pero, salvo este caso excepcional, entre los restantes 22 principales compradores nunca se realizó más del 40 por 100 de las adquisiciones anuales de la materia prima en los cinco primeros meses del año.

Como puede apreciarse, la estrategia de las adquisiciones era claramente inversa a la practicada en sus operaciones por algunos de los principales vendedores de materia prima. Si éstos trataban de aprovechar los beneficios derivados del alza estacional de los precios en los meses altos, aquéllos concentraban sus compras en los meses inmediatos a la cosecha, cuando los precios eran más bajos. Estos polos opuestos tenían, sin embargo, el denominador común de estar constituidos por personas que se dedicaban a la actividad comercial, aunque el tráfico que desarrollaban tenia un carácter distinto. Eran los grandes comerciantes sederos los que se beneficiaban de los bajos precios de la materia prima derivados de las ventas masivas realizadas por los cosecheros. Y eran también algunos de los grandes comerciantes que realizaban un tráfico de carácter diversificado los que aparecían como vendedores de seda precisamente en los meses altos, cuando la escasez de materia prima en el mercado provocaba el alza de los precios.

En todo caso, no parece descabellado pensar que la concentración de las 
compras en los meses centrales del año que solían realizar los grandes empresarios sederos acabaría provocando también una cierta estacionalidad en la dinámica de la sedería. Por mucho que tratasen de administrar el elevado volumen de materia prima adquirida a mediados del año, era lógico que ésta se consumiese mayoritariamente entre junio y diciembre, escaseando, por el contrario, en los cinco primeros meses del año. Quizá así pueda explicarse ese brusco descenso en las adquisiciones de los 22 principales compradores que aparece entre septiembre y diciembre, cuando se estaría consumiendo gran parte de la materia prima obtenida en los meses anteriores. E, igualmente, sería explicable que entre enero y mayo se intensificasen algo las compras con respecto al último cuatrimestre del año, puesto que el agotamiento de la materia prima acumulada obligaría a los empresarios a adquirir la escasa seda que apareciese en el mercado, a pesar de sus altos precios, con el fin de atender mínimamente las demandas más urgentes de sus corresponsales. De todas formas, lo más destacable es que la sedería podría experimentar una desaceleración de su actividad en esos cinco primeros meses del año. En este sentido, son muy frecuentes los testimonios de los artesanos en los que se alude a que la cosecha sedera sólo servía para abastecer a las fábricas durante algunos «cortos meses» del año. Y en el memorial confeccionado por algunos artesanos en 1772 instando a que el arte mayor constituyese una gran compañía de fabricantes se aludía expresamente a que aquella situación era una constante todos los años ${ }^{32}$. La propia evolución de los telares parados puede servir también para corroborar este fenómeno al efectuarse las visitas en épocas del año completamente distintas. Si en lugar de ordenarlas anualmente se disponen en función de los meses en que se efectuó la visita, se aprecia perfectamente que las cifras más elevadas se alcanzan entre enero y julio ${ }^{33}$, mes éste en que la seda de la nueva cosecha ya había recibido las operaciones previas necesarias para su utilización por los tejedores. No cabe duda que esta estacionalidad, que la importación de elevadas cantidades de seda extranjera sólo logró atenuar, constituiría uno de los diversos factores que dificultaron la modernización de la industria sedera valenciana.

"Los términos concretos cran los siguientes: a... Es digno de tenerse presente que la próxima cosecha de seda, aunque sea la más fértil y abundante, no será capaz de remediar la infelicidad y falta de hacienda que en el día se experimenta, pues sólo servirá para abastecer algunos cortos meses, como es experiencia práctica en todos los años..." (el subrayado es mío). AMV, Tribunal de Comercio, Año 1772, Exp. núm. 55, Fols. 11r-15r. Es cierto que los artesanos atribuían también este fenómeno a la acción deliberada de los comerciantes, yuienes, según su denuncia, sólo daban trabajo a las fábricas cuando recibian peticiones concretas de sus corresponsales. De todas formas, y aunque esto puede ser también cierto, creo que la parcial inactividad estacional de la sedería estaría determinada mayoritariamente por la escasez de materia prima.

"Sobre la falta de homogeneidad de los registros de telares y su posible utilización para reflejar la estacionadidad de la sederia, véase Franch (1989), p. 76, nota 51. 


\section{BIBLIOGRAFIA}

Ardit, M. (1985): «Las empresas comerciales de la sociedad Viuda de Don Mariano Canet e Hijos y las primeras expediciones directas de Valencia a Veracruz», Estudis-11. Valencia, pp. 103-142.

Franch, R. (1984): «Dinastías comerciales genovesas en la Valencia del siglo xvill: Los Causa, Batifora y Ferraro», Actas del II Coloquio de Metodologia Histórica Apli. cada. La docamentación notarial y la historia, Santiago de Compostela, vol. II, pp. 295.315.

- (1986): Crecimiento comercial y enriquecimiento burgués en la Valencia del siglo XVIII. Valencia, Institución Alfonso el Magnánimo.

- (1969 a): "La política de liberalización económica de Carlos III y la materia prima sedera valencianaw, Esludis-14. Valencia, pp. $51-81$.

- (1989 6): El capital comercial valenciano en el siglo XVIII, Valencia, Departamento de Historia Moderna.

FranCII, R., y ANDRÉS, F. (1983): “Aproximación al estudio de los canales de comercia. lización de la seda valenciana. El caso de la baronía de Alberique (1749-1804)», Saitabi, núm. XXXIII, Valencia, pp. 125.142.

Martínez Santos, V. (1981): Cara y cruz de la sedería valenciana (siglos XVIII-XIX), Valencia, Institución Alfonso el Magnánimo.

Morant, I. (1984): El declive del señorio, Valencia, Institución Alfonso el Magnánimo.

Olivares, P. (1976): El cultivo y la industria de la seda en Murcia en el siglo XVIII, Murcia.

Palop, J. M. (1977): Fluctuaciones de precios y abastecimeinto en la Valencia del siglo XVIII, Valencia, Institución Alfonso el Magnánimo.

Pérez Picazo, M. T., y Lemeunier, G. (1987): «La sericultura murciana. Producción, difusión y coyuntura. Siglos xui-XX», Revista de Historia Económica, año V, núm. 3, pp. 553-575. 


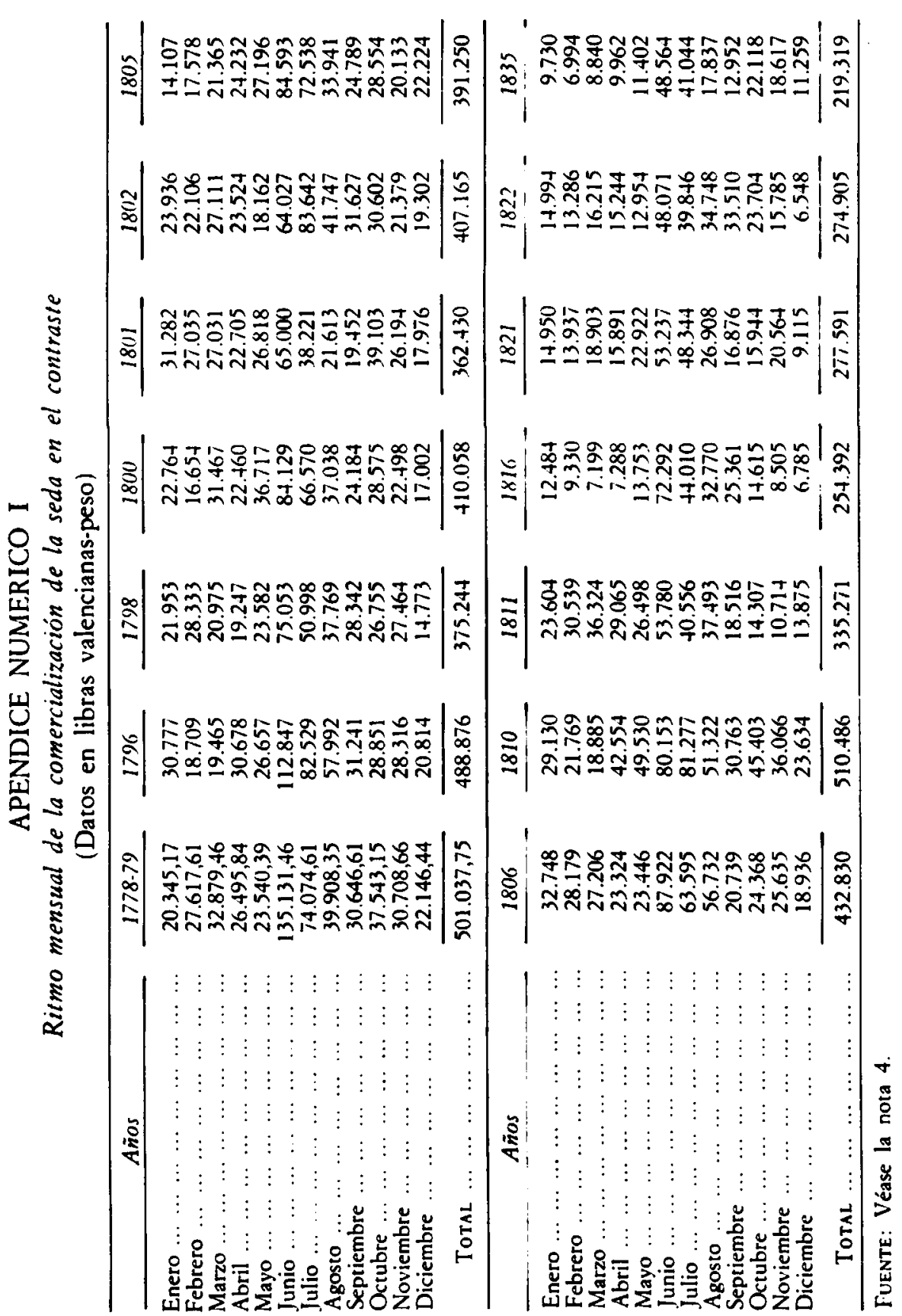




\section{MAPA 1}

El País Valenciano. División comarcal

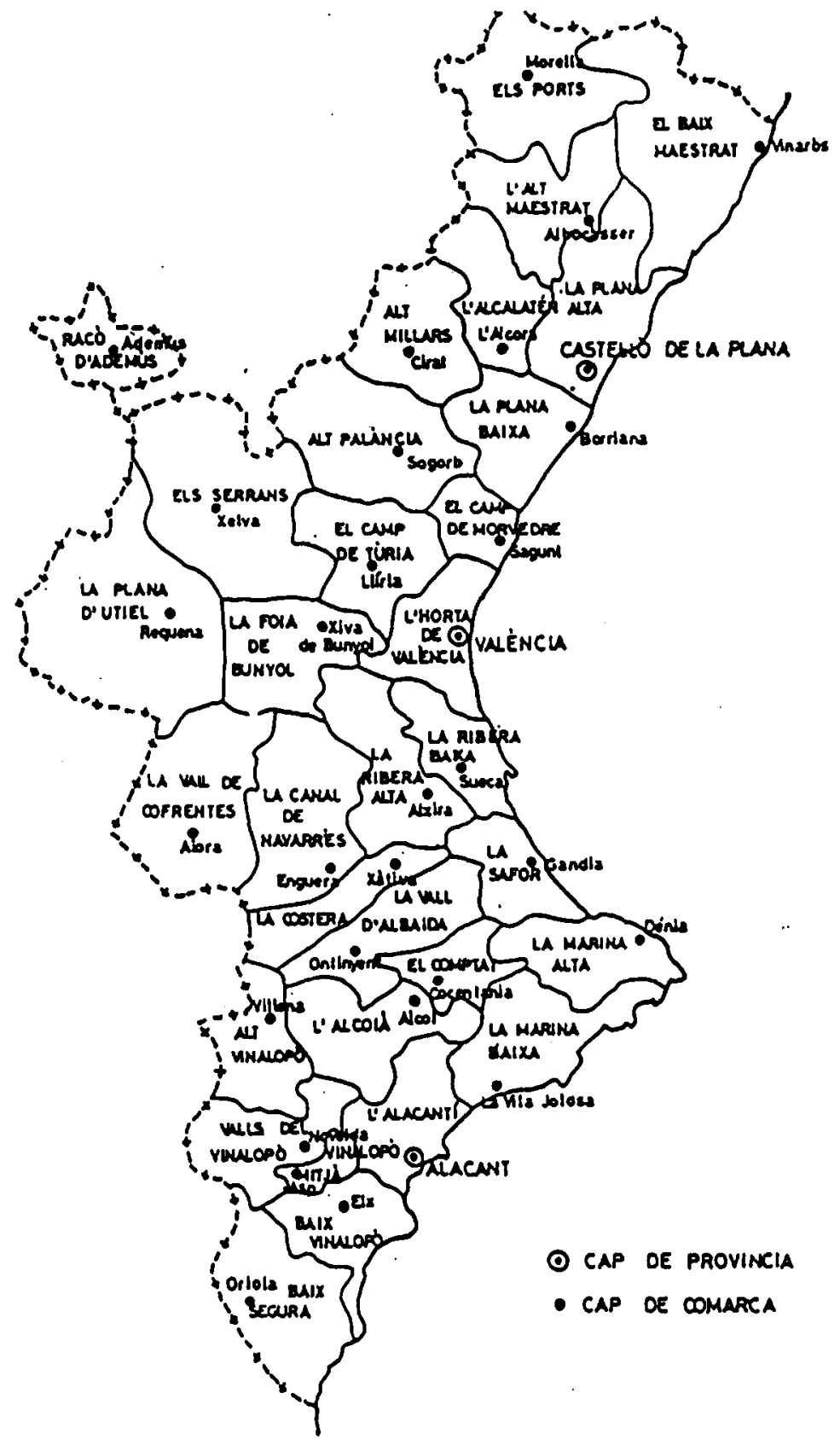

